\title{
Hidden Talents: Partnerships With Pareto-IMPRoving PRIVATE INFORMATION
}

\author{
by
}

Andrew F. Daughety and Jennifer F. Reinganum

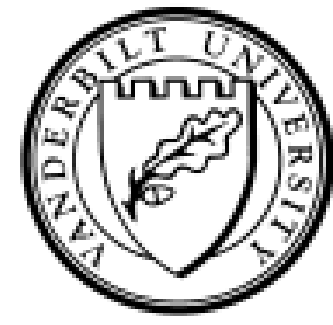

Working Paper No. 06-W13

June 2006

\section{DEPARTMENT OF ECONOMICS \\ VANDERBILT UNIVERSITY \\ NASHVILLE, TN 37235}

www.vanderbilt.edu/econ 
Hidden Talents: Partnerships with Pareto-Improving Private Information*

\author{
Andrew F. Daughety \\ Jennifer F. Reinganum \\ Department of Economics \\ and Law School \\ Vanderbilt University \\ Nashville, TN 37235 \\ andrew.f.daughety@vanderbilt.edu \\ jennifer.f.reinganum@vanderbilt.edu
}

May 2006, last revised June 2006

* We thank Huseyin Yildirim for suggestions on an earlier draft. 


\title{
Hidden Talents: Partnerships with Pareto-Improving Private Information
}

\author{
Andrew F. Daughety \\ Jennifer F. Reinganum
}

\begin{abstract}
Can the presence of private information in a transaction yield a Pareto-improvement over complete information? In this paper we show that the combination of multi-agent simultaneous signaling of private information, and the nature of the strategic interaction, can result in noncooperative equilibria which are Pareto superior to the complete-information non-cooperative equilibrium. Our application involves two agents who become partners in the production of a product (or the undertaking of a project). The partners' efforts are complementary and, in addition to its direct contribution to product quality, observable (but non-verifiable) effort serves as a signal for the unobservable component, talent; each partner is privately informed only about her own talent. Because the partners share the payoff from the project, each is tempted to shirk in providing effort. However, the need for each partner to signal the quality of the product to potential buyers serves as a credible commitment to provide greater effort. We find that this non-cooperative, simultaneous signaling need not be wasteful, and can actually be welfare-enhancing in the strongest sense: there is a portion of the parameter space wherein incomplete information is Pareto-improving relative to the complete-information non-cooperative outcome for all possible non-degenerate prior distributions over the private information. Therefore, the combination of simultaneous-move strategic interaction and incomplete information can lead to conditions wherein the "problem" of adverse selection actually mitigates the problem of moral hazard.
\end{abstract}




\section{Introduction.}

Can the presence of private information in a transaction yield a Pareto-improvement over complete information? In this paper we show that the combination of multi-agent simultaneous signaling of private information, and the nature of the strategic interaction, can result in noncooperative equilibria which are Pareto superior to the complete-information non-cooperative equilibrium: sellers and buyers can be made better off if some relevant information is private. In particular, we show how the distortion involved in signaling type can (in comparison with a complete-information non-cooperative equilibrium outcome) enhance the value of the product to buyers, which in turn results in a higher price and creates greater profits for the product's team of producers. More generally, we see how adverse selection can mitigate the moral hazard problem. In this sense, privacy is both individually and socially valuable.

Our application involves two agents who become partners in the production of a product (or in the undertaking of a project). For example, the partners might work to build a house, or to create a start-up company. Or perhaps the partners are simply two economists from different institutions who meet at a conference and decide to work on (and expect to complete) a joint paper during the period they are together; assume each partner has some degree of topic-specific expertise (e.g., one economist is a theorist and the other is an econometrician), and the topic is such that both specialities are needed. Alternatively, the "partners' may be separate firms who produce components that consumers combine (in, say, a 1:1 ratio) to generate a final product.

Expanding on the story of producing a house, output (the finished house) is produced through the complementary talents and efforts of both partners; perhaps one partner is a plumber/mason and the other is a carpenter/electrician. A partner's productivity is the sum of her talent and her effort. Thus productivity consists of both an observable part (effort) and an unobservable part (talent); each 
partner is privately informed only about her own talent. Effort is assumed to be observable but not verifiable (see, e.g., Grossman and Hart, 1986; Hart and Moore, 1990), and hence the partners themselves cannot contract over it; rather, we assume that they share the proceeds from the sale of the output equally.

Potential buyers are also assumed to be able to observe the partners' respective efforts, but cannot contract over effort since the buyers arrive on the scene after the effort investments have been made. In the case of building a house, this would be true of a house built "on spec;" alternatively, the product developed by a start-up company catches the attention of established firms, who might consider buying out the start-up. In addition to its direct contribution to product quality, observable effort serves as a signal for the unobservable component, talent. For instance, the superficial qualities of the elements of the house (and thus, the effort levels of the partners) may be assessed by a potential buyer via inspection; in addition, these effort levels are suggestive of the partners' talents, which give an indication of the quality of the work that is not subject to inspection (e.g., concealed portions of the construction).

Because the partners share the payoff from the project, each is tempted to shirk in providing effort. However, the need for each partner to signal the quality of the product to potential buyers serves as a credible commitment to provide greater effort. We find that this non-cooperative, simultaneous signaling need not be wasteful, and can actually be welfare-enhancing in the strongest sense: there is a portion of the parameter space wherein incomplete information is Pareto-improving relative to the complete-information non-cooperative outcome for all possible non-degenerate prior distributions over the private information. 


\section{Related Literature}

One strand of related literature deals with motivating agents within a partnership. In Morrison and Wilhelm(2004), a firm consists of overlapping generations of associates and partners. While young, associates obtain skills through mentoring by partners, and skilled associates are promoted to partnership; while old, partners mentor associates and then sell their shares in the firm. A partnership that promotes an unskilled associate is revealed as untrustworthy and can command only lower fees from future clients (and thus, the value of a partner's share is reduced). This provides sufficient incentive to motivate partners to engage in the costly process of mentoring associates. Thus, this model is one of pure moral hazard. Chou (forthcoming) provides a moralhazard-based model of partnership in which the key feature is "identity-mixing;" that is, the contribution of one partner to the success of a project may be mis-attributed to another partner. This modifies each partner's outside option (in bargaining over the proceeds) and can improve investment within the partnership. In Bar-Isaac (2003), there are overlapping generations of senior and junior workers. It is common knowledge that no one knows the ability of a junior worker, while a senior worker knows his own ability. Bar-Isaac shows that if: (1) there is identity-mixing so that the client cannot identify which worker was responsible for a successful project; and (2) the senior worker can specify in advance the price at which the junior worker can buy the firm, then the senior worker has an incentive to work in the second period because his failure would hurt the reputation of his junior partner, and only a junior partner with a good reputation will be willing to buy the firm. Thus a senior worker will pair with a junior partner of unknown quality in order to commit himself to exert effort (as he would otherwise shirk). Note that in this model, it is the common imperfect information about the junior worker's quality that is being used to leverage the senior worker's effort. In our 
model, both partners are tempted to shirk because each receives only half the value of the output. However, the need for each partner to signal the quality of the output to the potential buyers works against this temptation, with the result that private information about own-talent can result in a Pareto-improving increase in effort.

In a single-worker version of our model the more-talented type distorts her effort upwards (and consequently works too hard) in order to distinguish herself from her less-talented alter ego. Several previous single-worker models generate the result that agents work "too hard." Landers, Rebitzer and Taylor (1996) provide a screening model of a law firm, wherein an associate has private information about her type. In order to screen the associate, the partner offers her a menu of contracts. The contract designed for the more-talented associate involves higher compensation, but hours are distorted upward from the full-information level. In this case, the excessive effort is due to the associate's private information. In the career concerns model of Holmstrom (1982/1999) and Dewatripont, Jewitt and Tirole (1999), both a worker and a firm are symmetrically uncertain about the worker's talent. Since the worker's future compensation depends on the posterior expectation of his talent, he will exert excessive effort in an attempt to bias upward this posterior expectation. There is also a version of the career concerns model in which a worker has private information, and distorts his decision in order to improve the posterior expectation of his talent. Levy $(2004,2005)$ finds an "anti-herding" result in which a decision-maker breaks with the conventional wisdom more often in order to be perceived as having high ability. In contrast, Scharfstein and Stein (1990) and Zweibel (1995) find a "herding" result in which managers go along (too often) with the previous

\footnotetext{
1 Akerlof (1976), to which we return below, provides a multiple-worker model wherein workers work too hard.
} 
decisions of other managers. In our model, costly effort serves as a perfect signal of talent, and effort also impacts the partners' payoffs directly through increasing the value of the output; moreover, our model involves two partners who signal simultaneously to potential buyers.

We will not be addressing partnership formation, but there is a literature on this, starting with Akerlof's (1976) model of a rat race. For a recent contribution to the partnership-formation literature, see Levin and Tadelis (2005), in which the firm's output quality is the average quality of its workers, but clients may not be able to observe quality before purchase. In this model, there is no way for the partners to do any signaling to the client, since (for example) there is no effort choice involved, nor does the firm set the price of its output. In our model, the partners' types are private information relative to potential buyers and also to each other; they may, however, be signaled to potential buyers through observable effort.

There is a small literature involving simultaneous signaling in oligopoly markets. In some cases, firms know their rivals' types and use price and advertising to signal quality (e.g., Hertzendorf and Overgaard, 2001; Fluet and Garella, 2002) or use price to signal cost (e.g., Harrington, 1987; Bagwell and Ramey, 1991; and Orzach and Tauman, 1996). In other cases, each firm's type is its private information and price is used to signal quality (e.g., Daughety and Reinganum, ${ }^{2}$ forthcoming, and 2005b) or cost (e.g., Mailath, 1988, and 1989; Das Varma, 2003; Martin, 1995). We are not aware of any other simultaneous signaling models in which co-workers use effort to signal ability. ${ }^{3}$

2 Both of these papers show how strategic complementarity and incomplete information can soften price competition between oligopolists, and may lead to higher profits (though lower welfare).

3 In independent work, Gervais and Goldstein (2006) consider a partnership model with complementarities and moral hazard in which one partner has a positive self-perception bias regarding the importance of his contribution to the joint output. This bias essentially serves as a credible commitment for the biased agent to choose higher effort; due to the complementarity, the 
What effect does incomplete information typically have on welfare? Many simultaneousmove games have Bayes-Nash equilibria with lower surplus than their complete-information analogs. A good example is an optimal auction wherein incomplete information necessitates the use of a reserve price which can result in the seller inefficiently retaining the object. In the case of sequential games, we note that single-agent models involving screening typically result in some inefficiency, and we have already noted that the perfect Bayesian equilibria of single-agent signaling models typically result in lower ex ante expected payoffs due to the distortion that is often required to deter mimicry. Several of the multi-agent signaling models listed above involve the signaling agents benefitting from the need to signal, but this comes at the expense of other agents in the model (typically consumers; see, e.g., Harrington, 1987; Mailath, 1989; Orzach and Tauman, 1996; Daughety and Reinganum, forthcoming, and 2005b). In the present model, however, incomplete information provides perfect Bayesian equilibria whose payoffs represent a Pareto-improvement over the complete-information Nash payoffs.

The paper that is perhaps closest in spirit to ours is Hermalin (1998), which provides a model in which a team produces a product whose value depends on each member's effort and the state of the world; that is, $V=\theta \Sigma_{n} e_{n}$, where $e_{n}$ is worker n's effort level and $\theta$ is the state of the world. In Hermalin's model, team-members' effort levels are not complementary (as they are in ours); rather, each worker has a dominant strategy for providing effort that is increasing in $\theta$. Contracts cannot be written over effort (as is also true here), but the leader can receive a different share of $\mathrm{V}$ and side payments are allowed (we assume equal sharing and no side payments). A single team member who

unbiased agent will also increase effort. As a consequence, positive self-perception bias can improve the expected payoffs of both workers. Although some of our results have a similar flavor, it is important to distinguish our fully-rational signaling model from their behavioral model. 
knows the state of the world chooses her effort level first. The leader reveals the state of the world by choosing a higher level of effort than she would under symmetric information. The other teammembers correctly infer $\theta$ and then follow their $\theta$-contingent dominant strategies. Hermalin concludes that aggregate welfare is higher when the leader has private information as compared to the symmetric-information benchmark. However, since the leader works harder than the followers, it is unclear whether private information results in a Pareto-improvement. Based on the welfare measure of total surplus, Hermalin remarks (p. 1191) that "leading by example yields an outcome that is superior to the symmetric information outcome. The reason for this surprising conclusion is that the hidden information problem counteracts the teams problem (free-riding)."

Our model is quite different from Hermalin's. In our model, there is no common state of the world, since each partner has her own privately-known type. In Hermalin's model, the leader serves a coordination function by focusing all of the workers on the correct (common) state of the world. In our model, the partners move simultaneously and thus do not signal to each other; rather, they signal non-cooperatively to potential buyers. Furthermore, in Hermalin's model, the team-members may make side payments to each other, while this cannot occur in our model. As in Hermalin (1998), our broad conclusion is that adverse selection can mitigate the moral hazard problem, but now the welfare improvement is stronger since it is a Pareto-improvement rather than just an increase in total surplus, and the simultaneity of movement by the privately- (but only partially-) informed partners means that this result does not rely on any coordination arising from sequentiality.

\section{Plan of the Paper}

In Section 2 we develop the basic model and provide the equilibrium under both complete information and incomplete information. Section 3 uses a combination of analytical and numerical 
techniques ${ }^{4}$ to compare the equilibria, both in terms of effort and ex ante expected payoffs, under the two information regimes. Section 4 provides a summary of results and a discussion of possible extensions. There are two appendices; the Appendix contains the derivations and proofs for the most significant aspects of the analysis while the Supplementary Appendix contains the more mundane proofs.

2. Model Setup and Equilibrium under Complete and Incomplete Information

We model the problem as a one-shot, three-stage game. In the first stage, Nature chooses a type for each partner (talent, $t_{i}$, for partners $\left.i=1,2\right)$. The type can be high $\left(t_{H}\right)$ or low $\left(t_{L}\right)$, with the probability of high being $\lambda$, a positive fraction (i.e., $\left.\operatorname{Pr}\left\{\mathrm{t}_{\mathrm{i}}=\mathrm{t}_{\mathrm{H}}\right\}=\lambda \in(0,1), \mathrm{i}=1,2\right)$; Nature's draws are i.i.d and $0<t_{L}<t_{H}<1 .{ }^{5}$ Furthermore, let $\bar{t} \equiv \lambda t_{H}+(1-\lambda) t_{L}$; that is, $\bar{t}$ is the expected talent for either partner. If the game is one of complete information, then in the second stage both partners observe the vector of types and each chooses her effort level independently and simultaneously with the other partner. Partners act in a non-cooperative manner under both complete and incomplete information, as we take both effort and talent to be non-verifiable, so that no contract that induces cooperative behavior can be written. If the game is one of incomplete information, then each partner's type is her private information and each chooses her effort level independently and simultaneously with the other partner. Either way, the partners complete the project; the value of

${ }^{4}$ The numerical analysis employed Mathematica ${ }^{\circledR}$ 5.2. Copies of the relevant notebooks are available upon request from the authors.

${ }^{5}$ One could extend the definitions of the talent-values beyond the indicated domain, but this would necessitate additional parametric complexity which would not contribute to the insights from the analysis. 
the project, $\mathrm{V}$, is the product of the partners' productivities, where each partner's productivity is the sum of her talent and her effort (e.g., $\mathrm{P}_{\mathrm{i}}=\mathrm{t}_{\mathrm{i}}+\mathrm{e}_{\mathrm{i}}$ in the case of complete information).

Finally, in the third stage, at least two homogeneous buyers bid for the completed project. Each buyer has unit demand, with reservation value equal to the actual (in the case of complete information) or inferred (in the case of incomplete information) value of the project. In the case of complete information, buyers can observe $\left\{\mathrm{t}_{\mathrm{i}}, \mathrm{e}_{\mathrm{i}}\right\}$ for $\mathrm{i}=1,2$, while in the case of incomplete information, buyers observe individual effort levels $\left\{\mathrm{e}_{\mathrm{i}}\right\}, \mathrm{i}=1,2$, and form beliefs about the individual talents based on the observed effort levels, resulting in perceived talents $\left\{\tilde{\mathrm{t}}_{\mathrm{i}}\right\}, \mathrm{i}=1,2$. In all circumstances the two partners are assumed to split the returns from the sale of the project equally; because demand exceeds supply, the partnership is able to extract the full perceived value of the project. Lastly, each partner incurs a quadratic cost of exerting effort, captured by the term $\left(\mathrm{e}_{\mathrm{i}}\right)^{2} /\left(4 \mathrm{t}_{\mathrm{i}}\right), \mathrm{i}=1,2$; as indicated, such costs are decreasing in the level of partner $\mathrm{i}$ 's talent.

Therefore, the payoff that partner i receives from the project, $u_{i}\left(e_{i}, t_{i}, \widetilde{t}_{i} \mid e_{j}, \widetilde{t}_{j}\right)$, is:

$$
\left.\mathrm{u}_{\mathrm{i}}\left(\mathrm{e}_{\mathrm{i}}, \mathrm{t}_{\mathrm{i}}, \widetilde{\mathrm{t}}_{\mathrm{i}}\right) \mathrm{e}_{\mathrm{j}}, \widetilde{\mathrm{t}}_{\mathrm{j}}\right) \equiv\left(\widetilde{\mathrm{t}}_{\mathrm{i}}+\mathrm{e}_{\mathrm{i}}\right)\left(\widetilde{\mathrm{t}}_{\mathrm{j}}+\mathrm{e}_{\mathrm{j}}\right) / 2-\left(\mathrm{e}_{\mathrm{i}}\right)^{2} /\left(4 \mathrm{t}_{\mathrm{i}}\right), \quad \mathrm{i}, \mathrm{j}=1,2, \mathrm{j} \neq \mathrm{i}
$$

That is, partner i's payoff is a function of her effort, her true and perceived types $\left(\mathrm{t}_{\mathrm{i}}\right.$ and $\tilde{\mathrm{t}}_{\mathrm{i}}$, respectively), and her partner's perceived total productivity (that is, $\widetilde{\mathfrak{t}}_{\mathrm{j}}+\mathrm{e}_{\mathrm{j}}$ ).

\section{Complete Information}

As indicated above, under complete information both talents are observable by each partner as well as the buyers. Thus, buyers will bid up the price of the project to its value $\mathrm{V}$, where $\mathrm{V}=\mathrm{P}_{\mathrm{i}} \mathrm{P}_{\mathrm{j}}$, so that partner $\mathrm{i}$ chooses $\mathrm{e}_{\mathrm{i}}$ to maximize her payoff:

$$
\mathrm{u}_{\mathrm{i}}\left(\mathrm{e}_{\mathrm{i}}, \mathrm{t}_{\mathrm{i}}, \mathrm{t}_{\mathrm{i}} \mid \mathrm{e}_{\mathrm{j}}, \mathrm{t}_{\mathrm{j}}\right) \equiv\left(\mathrm{t}_{\mathrm{i}}+\mathrm{e}_{\mathrm{i}}\right)\left(\mathrm{t}_{\mathrm{j}}+\mathrm{e}_{\mathrm{j}}\right) / 2-\left(\mathrm{e}_{\mathrm{i}}\right)^{2} /\left(4 \mathrm{t}_{\mathrm{i}}\right), \quad \mathrm{i}, \mathrm{j}=1,2, \mathrm{j} \neq \mathrm{i}
$$

Given that the partners are non-cooperatively choosing effort levels, a convenient form (abusing 
notation) for partner $i$ 's payoff is $u_{i}\left(e_{i}, t_{i}, t_{i} \mid P_{j}\right)=\left(t_{i}+e_{i}\right) P_{j} / 2-\left(e_{i}\right)^{2} /\left(4 t_{i}\right)$. Solving partner $i$ 's decision problem:

$$
\mathrm{e}_{\mathrm{i}}=\arg \max _{\mathrm{e}} \mathrm{u}_{\mathrm{i}}\left(\mathrm{e}, \mathrm{t}_{\mathrm{i}}, \mathrm{t}_{\mathrm{i}} \mid \mathrm{P}_{\mathrm{j}}\right),
$$

we obtain i's best response function, $e_{i}=t_{i} P_{j}=t_{i}\left(t_{j}+e_{j}\right)$. Notice that $i$ 's best-response function is upward-sloping in partner j's effort level, so that effort levels are strategic complements.

Let $\mathrm{e}_{\mathrm{rs}}$ be the equilibrium effort level for partner i when her type is $r$ and her partner's type is $s(r, s=H, L)$, so that we obtain:

$$
\mathrm{e}_{\mathrm{rs}}=\mathrm{t}_{\mathrm{r}} \mathrm{t}_{\mathrm{s}}\left(1+\mathrm{t}_{\mathrm{r}}\right) /\left(1-\mathrm{t}_{\mathrm{r}} \mathrm{t}_{\mathrm{s}}\right), \quad \mathrm{r}, \mathrm{s}=\mathrm{H}, \mathrm{L} .
$$

It is straightforward to show that the equilibrium effort level is increasing in the talent of either partner. Similarly, it is straightforward to show that the equilibrium payoff for partner $i$ when her type is $r$ and her partner's type is $s(r, s=H, L)$, denoted as $u_{r s}$, is:

$$
\mathrm{u}_{\mathrm{rs}}=\mathrm{t}_{\mathrm{r}} \mathrm{t}_{\mathrm{s}}\left(1+\mathrm{t}_{\mathrm{r}}\right)\left(2+\mathrm{t}_{\mathrm{s}}\left(1-\mathrm{t}_{\mathrm{r}}\right)\right) /\left[4\left(1-\mathrm{t}_{\mathrm{r}} \mathrm{t}_{\mathrm{s}}\right)^{2}\right] \quad \mathrm{r}, \mathrm{s}=\mathrm{H}, \mathrm{L},
$$

and that $\mathrm{u}_{\mathrm{rs}}$ is increasing in the talent of either partner. With a little algebra one can show that $\mathrm{u}_{\mathrm{HL}}$ $>\mathrm{u}_{\mathrm{LH}}$ which, along with the previous statement about positive partial derivatives, implies that:

$$
\mathrm{u}_{\mathrm{HH}}>\mathrm{u}_{\mathrm{HL}}>\mathrm{u}_{\mathrm{LH}}>\mathrm{u}_{\mathrm{LL}}
$$

That is, under complete information, a partner obtains a higher ex post equilibrium payoff from being an H-type than from being an L-type, and a higher ex post equilibrium payoff when matched with an H-type partner rather than an L-type partner.

Finally, the ex ante expected payoff for either partner under complete information, which we denote as $\mathrm{U}^{\mathrm{CI}}$, is:

$$
\mathrm{U}^{\mathrm{CI}} \equiv \lambda^{2} \mathrm{u}_{\mathrm{HH}}+\lambda(1-\lambda) \mathrm{u}_{\mathrm{HL}}+(1-\lambda) \lambda \mathrm{u}_{\mathrm{LH}}+(1-\lambda)^{2} \mathrm{u}_{\mathrm{LL}}
$$

$\mathrm{U}^{\mathrm{CI}}$ is strictly increasing in $\lambda$ (this is shown in the Supplementary Appendix). These ex ante payoffs 
are the same for each partner (and, thus, we have dropped the index for the partner), since Nature's draws for partner-types in stage one are i.i.d.

\section{Incomplete Information}

As indicated earlier, by incomplete information we mean that each partner's type is her private information. The equilibrium notion we will employ is perfect Bayesian equilibrium, and we will focus on symmetric separating equilibria, so this means that we must specify beliefs for the buyers about the partners' types for the equilibrium. In equilibrium these beliefs must be correct and allow the types to separate, so that when the partners individually and simultaneously choose effort levels in the second stage, each chooses effort so as to maximize her expected payoff, where the expectation is over her partner's possible types, and accounts for the beliefs that buyers will hold. Finally, separation will require these choices to respect appropriately-defined incentive compatibility constraints.

We have assumed that effort levels are observable to buyers, so that effort levels may signal information about talent to the buyers. Since the partners move simultaneously, when talent is private information we assume that each partner's effort level cannot signal information about the other partner's type. ${ }^{6}$ Since the partners are identical ex ante, we will treat them identically and therefore restrict beliefs to be independent of identity. Thus, the perceived level of talent for partner $\mathrm{i}, \tilde{\mathrm{t}}_{\mathrm{i}}$, is based on partner $\mathrm{i}$ 's observed effort, $\mathrm{e}_{\mathrm{i}}$, and is captured by the notation $\mu\left(\mathrm{e}_{\mathrm{i}}\right)$, where $\mu(\bullet) \in$ $\left\{t_{H}, t_{L}\right\}$. Suppose that partner $\mathrm{j}$ uses a separating equilibrium strategy denoted as $\mathrm{e}^{*}(\mathrm{t})$. Then partner i predicts that j's productivity will be - and the buyers will perceive it to be $-\left(t_{H}+e^{*}\left(t_{H}\right)\right)$ with

${ }^{6}$ Fudenberg and Tirole (1991, pp. 332-3) incorporate this restriction on beliefs, which they refer to as "no signaling what you don't know," into their definition of perfect Bayesian equilibrium for a general class of abstract games, of which ours is a special case. 
probability $\lambda$ and $\left(t_{L}+e^{*}\left(t_{L}\right)\right)$ with probability $(1-\lambda)$. Therefore, partner i chooses an effort level so as to maximize her expected payoff, where the expectation is taken over partner j's type. Due to the linearity of partner i's payoff in partner j's productivity, the expectation passes through; we denote partner j's expected productivity as $\mathrm{P}^{*} \equiv \mathrm{E}\left[\mathrm{t}_{\mathrm{j}}+\mathrm{e}^{*}\left(\mathrm{t}_{\mathrm{j}}\right)\right]$. Thus, given the form of the payoff function for partner $i$ and that we focus on a separating equilibrium, the payoff function can be reexpressed as $\mathrm{u}_{\mathrm{i}}\left(\mathrm{e}_{\mathrm{i}}, \mathrm{t}_{\mathrm{i}}, \mu\left(\mathrm{e}_{\mathrm{i}}\right) \mid \mathrm{P}^{*}\right)$. In order for this to be a separating equilibrium, it must be true that types are as well-off choosing revealing levels of effort as they could be by choosing some other level of effort that may induce consumers to believe that partner $i$ is of the alternative type. Formally, we write this as requiring equilibrium effort levels $\left(\mathrm{e}_{\mathrm{H}}, \mathrm{e}_{\mathrm{L}}\right)$ such that the following incentive compatibility and consistency of beliefs conditions hold:

$$
\begin{aligned}
& \mathrm{u}_{\mathrm{i}}\left(\mathrm{e}_{\mathrm{H}}, \mathrm{t}_{\mathrm{H}}, \mathrm{t}_{\mathrm{H}} \mid \mathrm{P}^{*}\right) \geq \max _{\mathrm{e}} \mathrm{u}_{\mathrm{i}}\left(\mathrm{e}, \mathrm{t}_{\mathrm{H}}, \mu(\mathrm{e}) \mid \mathrm{P}^{*}\right) \quad \mathrm{i}, \mathrm{j}=1,2, \mathrm{j} \neq \mathrm{i} ; \\
& \mathrm{u}_{\mathrm{i}}\left(\mathrm{e}_{\mathrm{L}}, \mathrm{t}_{\mathrm{L}}, \mathrm{t}_{\mathrm{L}} \mid \mathrm{P}^{*}\right) \geq \max _{\mathrm{e}} \mathrm{u}_{\mathrm{i}}\left(\mathrm{e}, \mathrm{t}_{\mathrm{L}}, \mu(\mathrm{e}) \mid \mathrm{P}^{*}\right) \quad \mathrm{i}, \mathrm{j}=1,2, \mathrm{j} \neq \mathrm{i} ; \\
& \mathrm{t}_{\mathrm{H}}=\mu\left(\mathrm{e}_{\mathrm{H}}\right)=\mu\left(\mathrm{e}^{*}\left(\mathrm{t}_{\mathrm{H}}\right)\right) \text { and } \mathrm{t}_{\mathrm{L}}=\mu\left(\mathrm{e}_{\mathrm{L}}\right)=\mu\left(\mathrm{e}^{*}\left(\mathrm{t}_{\mathrm{L}}\right)\right)
\end{aligned}
$$

Thus, in the symmetric separating perfect Bayesian equilibrium, type $\mathrm{H}$ (respectively, L) can signal type via effort level $\mathrm{e}_{\mathrm{H}}\left(\right.$ respectively, $\left.\mathrm{e}_{\mathrm{L}}\right)$. Note further that (7a) and (7b) also serve to define bestresponse functions, when viewed as what partner i should choose given the expected productivity of partner $\mathrm{j}\left(\mathrm{P}^{*}\right)$. Therefore, since this is a symmetric equilibrium, one further requirement is that this conjectured expected productivity of i's partner be correct in equilibrium:

$$
\mathrm{P}^{*}=\lambda\left(\mathrm{t}_{\mathrm{H}}+\mathrm{e}_{\mathrm{H}}\right)+(1-\lambda)\left(\mathrm{t}_{\mathrm{L}}+\mathrm{e}_{\mathrm{L}}\right) .
$$

That is, the expected productivity for each partner in the conditioning statement for the incentive compatibility constraints ( $7 a$ ) and ( $7 b$ ) must be the expected value of the productivities that can arise in equilibrium. We now use the discussion above to define formally the equilibrium of interest. 
Definition: A symmetric separating perfect Bayesian equilibrium (SSPBE) consists of a pair of effort levels $\left(\mathrm{e}_{\mathrm{H}}^{*}, \mathrm{e}_{\mathrm{L}}^{*}\right)$ and beliefs $\mu^{*}(\mathrm{e})$ such that conditions $(7 \mathrm{a})-(7 \mathrm{~d})$ are satisfied.

As is shown in the Appendix, while algebraically messy, a unique (refined) SSPBE always exists; uniqueness of the equilibrium is the result of the application of the Intuitive Criterion (Cho and Kreps, 1987):

Proposition 1: A unique (refined) SSPBE always exists; it is defined implicitly by the following (parameter-dependent) equations.

$$
\begin{aligned}
& \mathrm{P}^{*}= \begin{cases}\mathrm{P}^{+} \equiv \overline{\mathrm{t}}+\mathrm{t}_{\mathrm{L}} \mathrm{P}^{+}+\lambda\left[2 \mathrm{t}_{\mathrm{L}}\left(\mathrm{t}_{\mathrm{H}}-\mathrm{t}_{\mathrm{L}}\right) \mathrm{P}^{+}\right]^{1 / 2} & \text { when } \overline{\mathrm{t}} /(1-\overline{\mathrm{t}})<2 \mathrm{t}_{\mathrm{L}} /\left(\mathrm{t}_{\mathrm{H}}-\mathrm{t}_{\mathrm{L}}\right) \\
\mathrm{P}^{0} \equiv \overline{\mathrm{t}} /(1-\overline{\mathrm{t}}) & \text { when } \overline{\mathrm{t}} /(1-\overline{\mathrm{t}}) \geq 2 \mathrm{t}_{\mathrm{L}} /\left(\mathrm{t}_{\mathrm{H}}-\mathrm{t}_{\mathrm{L}}\right)\end{cases} \\
& \mathrm{e}_{\mathrm{H}}^{*}= \begin{cases}\mathrm{e}_{\mathrm{H}}^{+} \equiv \mathrm{t}_{\mathrm{L}} \mathrm{P}^{+}+\left[2 \mathrm{t}_{\mathrm{L}}\left(\mathrm{t}_{\mathrm{H}}-\mathrm{t}_{\mathrm{L}}\right) \mathrm{P}^{+}\right]^{1 / 2} & \text { when } \overline{\mathrm{t}} /(1-\overline{\mathrm{t}})<2 \mathrm{t}_{\mathrm{L}} /\left(\mathrm{t}_{\mathrm{H}}-\mathrm{t}_{\mathrm{L}}\right) \\
\mathrm{e}_{\mathrm{H}}^{0} \equiv \mathrm{t}_{\mathrm{H}} \mathrm{P}^{0} & \text { when } \overline{\mathrm{t}} /(1-\overline{\mathrm{t}}) \geq 2 \mathrm{t}_{\mathrm{L}} /\left(\mathrm{t}_{\mathrm{H}}-\mathrm{t}_{\mathrm{L}}\right)\end{cases} \\
& \mathrm{e}_{\mathrm{L}}^{*}=\mathrm{t}_{\mathrm{L}} \mathrm{P}^{*} \\
& \mu^{*}(\mathrm{e})=\mathrm{t}_{\mathrm{H}} \text { if } \mathrm{e} \geq \mathrm{e}_{\mathrm{H}}^{*}, \text { else } \mu^{*}(\mathrm{e})=\mathrm{t}_{\mathrm{L}} .
\end{aligned}
$$

(The explicit version of $\mathrm{P}^{+}$is provided in the Appendix). Proposition 1 indicates two important points. First, there always exists a unique (refined) SSPBE. Second, its nature changes as a function of whether the incentive compatibility constraint (7b) is "tight" or "slack" in the SSPBE (constraint (7a) on the high type is always slack in the equilibrium selected). When constraint (7b) is slack, it is because the parameters of the game $\left(\lambda, t_{H}\right.$, and $\left.t_{L}\right)$ are such that separation allows both types to follow their undistorted best-response functions, namely $\mathrm{e}_{\mathrm{r}}^{*}=\mathrm{t}_{\mathrm{r}} \mathrm{P}^{0}, \mathrm{r}=\mathrm{H}, \mathrm{L}$, where the superscript " 0 " denotes the fact that no distortion (relative to the best-response function) is needed to signal 
type. Substituting the equilibrium value of $\mathrm{P}^{0}$ immediately yields the equilibrium effort levels $\mathrm{e}_{\mathrm{r}}^{*}=$ $\mathrm{t}_{\mathrm{r}} \mathrm{t} /(1-\overline{\mathrm{t}}), \mathrm{r}=\mathrm{H}, \mathrm{L}$. Notice that the form of the best-response functions in this case is similar to the form of the best-response functions in the complete-information case (where $\mathrm{e}_{\mathrm{i}}=\mathrm{t}_{\mathrm{i}} \mathrm{P}_{\mathrm{j}}$ ), though the actual value of $P^{0}$ is different from $P_{j}$. Condition (7b) is slack when $\bar{t} /(1-\bar{t}) \geq 2 t_{L} /\left(t_{H}-t_{L}\right)$, and we refer to this type of equilibrium as a "Non-distortionary" SSPBE, or NPBE for short. ${ }^{7}$ It is straightforward to show that, in any NPBE, $\mathrm{P}^{0}, \mathrm{e}_{\mathrm{H}}^{0}$, and $\mathrm{e}_{\mathrm{L}}^{0}\left(\equiv \mathrm{e}_{\mathrm{L}}^{*}=\mathrm{t}_{\mathrm{L}} \mathrm{P}^{0}\right)$ are all increasing functions of $\lambda, t_{H}$, and $t_{L}$. Thus (for example), an exogenous increase in individual talents increases noncooperative equilibrium effort levels.

When the incentive compatibility condition (7b) is tight, then the H-type partner needs to distort her effort upwards (relative to the NPBE best response) in order to separate from the signal sent by the L-type partner: that is, the H-type distorts so as to send a signal that makes the L-type indifferent between mimicking and choosing an effort based on her (NPBE) best response. We refer to such equilibria as "Distortionary" SSPBE, or DPBE for short; these equilibria occur when $\bar{t} /(1-\bar{t})$ $<2 t_{\mathrm{L}} /\left(\mathrm{t}_{\mathrm{H}}-\mathrm{t}_{\mathrm{L}}\right)$. Thus, the SSPBE come in two flavors, DPBE and NPBE, and Proposition 1 provides the regions of the parameter space associated with one or the other SSPBE. As with the NPBE, the DPBE comparative statics for $\mathrm{P}^{+}, \mathrm{e}_{\mathrm{H}}^{+}$, and $\mathrm{e}_{\mathrm{L}}^{+}\left(\equiv \mathrm{e}_{\mathrm{L}}^{*}=\mathrm{t}_{\mathrm{L}} \mathrm{P}^{+}\right)$with respect to $\lambda$ and $\mathrm{t}_{\mathrm{H}}$ are straightforward (all three equilibrium values are increasing in these two parameters); unfortunately, this is not true for the effect of changes in $t_{L}$, as the algebra precludes providing a clear sign for these derivatives. We formalize the foregoing comparative statics results in Proposition 2 below.

${ }^{7}$ Both types of SSPBE, the NPBE and the one to be detailed below as a "distortionary" PBE are, in fact, distorted relative to the complete-information equilibrium. Thus, the use of the words "non-distortionary" and "distortionary" is to differentiate the two types of SSPBE based on whether the "no mimicry" by type L incentive constraint (7b) is slack or tight, respectively. 


\section{Proposition 2.}

i) In any SSPBE, $\mathrm{e}_{\mathrm{r}}^{*}, \mathrm{r}=\mathrm{H}, \mathrm{L}$, is increasing in $\lambda$ and $\mathrm{t}_{\mathrm{H}}$.

ii) In any NPBE, $e_{r}^{*}, r=H, L$, is increasing in $t_{L}$.

Typically, in monopoly signaling models, the only aspect of the prior distribution that affects the separating equilibrium is the distribution's support. ${ }^{8}$ Here, however, an increase in the likelihood that a partner has the high level of talent $(\lambda)$ increases effort by both possible types of partner. This is because of the fact that effort levels are strategic complements, and that the best response depends upon the expected value of the other partner's type. Therefore the higher the expected value of i's partner's type (as a result of increasing $\lambda$ ), the higher is partner i's best response. Thus, the separating equilibrium is responsive not only to the support of the prior distribution over the type space, but also to the details (here, the magnitude of $\lambda$ ) of the prior as well. ${ }^{9}$ This dependence of the SSPBE on $\lambda$ provides a further avenue of exploration which we consider later in the paper.

In the second stage of the game, each partner knows her type, but not her partner's type, leading to the interim payoffs for the high and low types, $\mathrm{U}_{\mathrm{H}}^{\mathrm{II}}$ and $\mathrm{U}_{\mathrm{L}}^{\mathrm{II}}$, respectively:

$$
\mathrm{U}_{\mathrm{H}}^{\mathrm{II}} \equiv \lambda \mathrm{u}_{\mathrm{i}}\left(\mathrm{e}_{\mathrm{H}}^{*}, \mathrm{t}_{\mathrm{H}}, \mathrm{t}_{\mathrm{H}} \mid \mathrm{e}_{\mathrm{H}}^{*}, \mathrm{t}_{\mathrm{H}}\right)+(1-\lambda) \mathrm{u}_{\mathrm{i}}\left(\mathrm{e}_{\mathrm{H}}^{*}, \mathrm{t}_{\mathrm{H}}, \mathrm{t}_{\mathrm{H}} \mid \mathrm{e}_{\mathrm{L}}^{*}, \mathrm{t}_{\mathrm{L}}\right) ;
$$

and

$$
\mathrm{U}_{\mathrm{L}}^{\mathrm{II}} \equiv \lambda \mathrm{u}_{\mathrm{i}}\left(\mathrm{e}_{\mathrm{L}}^{*}, \mathrm{t}_{\mathrm{L}}, \mathrm{t}_{\mathrm{L}} \mid \mathrm{e}_{\mathrm{H}}^{*}, \mathrm{t}_{\mathrm{H}}\right)+(1-\lambda) \mathrm{u}_{\mathrm{i}}\left(\mathrm{e}_{\mathrm{L}}^{*}, \mathrm{t}_{\mathrm{L}}, \mathrm{t}_{\mathrm{L}} \mid \mathrm{e}_{\mathrm{L}}^{*}, \mathrm{t}_{\mathrm{L}}\right) .
$$

Thus, the ex ante expected payoff to a partner under incomplete information, denoted as $\mathrm{U}^{\mathrm{II}}$, is:

8 A few exceptions do exist; see Matthews and Mirman (1983), Caillaud and Hermalin (1993), and Daughety and Reinganum (1995, and 2005a).

${ }^{9}$ Other models with this information structure and multiple players also obtain this kind of prior-dependence; see Mailath (1988, and 1989), Das Varma (2003) and Daughety and Reinganum (forthcoming, and 2005b). 


$$
\mathrm{U}^{\mathrm{II}} \equiv \lambda \mathrm{U}_{\mathrm{H}}^{\mathrm{II}}+(1-\lambda) \mathrm{U}_{\mathrm{L}}^{\mathrm{II}}
$$

its exact form is provided in the Appendix, along with the proof of the following proposition providing comparative statics results.

Proposition 3. In all SSPBE:

i) $\mathrm{U}_{\mathrm{H}}^{\mathrm{II}}>\mathrm{U}_{\mathrm{L}}^{\mathrm{II}}$;

ii) $\mathrm{U}_{\mathrm{H}}^{\mathrm{II}}$ and $\mathrm{U}_{\mathrm{L}}^{\mathrm{II}}$ are increasing functions of $\lambda$;

iii) $\mathrm{U}^{\mathrm{II}}$ is an increasing function of $\lambda$.

Thus, from an interim equilibrium perspective, it is always better to be an H-type than to be an Ltype, and the interim equilibrium payoffs for both types are increasing in the prior probability that a partner will be an H-type. This is also a result of the interplay between incomplete information and the strategic complementarity of effort levels. Finally, given the foregoing, the third result follows, namely that the ex ante expected payoff to being a partner in the incomplete-information game is increasing in the prior probability that a partner is an H-type.

We now explore the geometry of the parameter space (i.e., the $\lambda$, $t_{H}$ and $t_{L}$ values) that produces the two types of equilibria; in order to do this we focus on $\left(t_{H}, t_{L}\right)$-space. Using the condition $\bar{t} /(1-\bar{t})=2 t_{L} /\left(t_{H}-t_{L}\right)$, which defines the boundary between DPBE and NPBE, and solving for $\lambda$ as a function of $t_{H}$ and $t_{L}$, we define $\Lambda\left(t_{H}, t_{L}\right)$ as:

$$
\Lambda\left(t_{H}, t_{L}\right) \equiv t_{L}\left(2-\left(t_{H}+t_{L}\right)\right) /\left(\left(t_{H}+t_{L}\right)\left(t_{H}-t_{L}\right)\right) .
$$

It is straightforward to show that $\Lambda\left(t_{H}, t_{L}\right)$ is increasing in $t_{L}$ (see the Supplementary Appendix). Recall that $\mathrm{t}_{\mathrm{L}}<\mathrm{t}_{\mathrm{H}}$ and let:

$$
\left(\mathrm{t}_{\mathrm{H}}, \mathrm{t}_{\mathrm{L}}\right) \equiv\left\{\lambda \in(0,1) \mid \lambda<\min \left[\Lambda\left(\mathrm{t}_{\mathrm{H}}, \mathrm{t}_{\mathrm{L}}\right), 1\right]\right\} ;
$$

and 


$$
\eta\left(t_{H}, t_{L}\right) \equiv\left\{\lambda \in(0,1) \mid \lambda \geq \min \left[\Lambda\left(t_{H}, t_{L}\right), 1\right]\right\}
$$

The sets $\&\left(t_{H}, t_{L}\right)$ and $\eta\left(t_{H}, t_{L}\right)$ partition the possible values of $\lambda$ into those that will, at the given point $\left(t_{H}, t_{L}\right)$, result in an SSPBE which is (respectively) a DPBE or an NPBE; note that $\left(_{H}, t_{L}\right)$ could be empty. This leads to the following proposition which formalizes the foregoing:

\section{Proposition 4.}

i) For the portion of the $\left(t_{H}, t_{L}\right)$ parameter space wherein $\Lambda\left(t_{H}, t_{L}\right) \geq 1$, every possible prior leads to a distortionary SSPBE. That is, for all $t_{H}$ and $t_{L}$ such that $\Lambda\left(t_{H}, t_{L}\right) \geq 1$, the unique SSPBE is a DPBE for all $\lambda \in(0,1)$.

ii) For values of $t_{H}$ and $t_{L}$ such that $0<\Lambda\left(t_{H}, t_{L}\right)<1$, then the SSPBE is a DPBE when $\lambda<\Lambda\left(t_{\mathrm{H}}, \mathrm{t}_{\mathrm{L}}\right)$, while the SSPBE is an NPBE when $\lambda \geq \Lambda\left(\mathrm{t}_{\mathrm{H}}, \mathrm{t}_{\mathrm{L}}\right)$.

Figure 1 below illustrates the regions wherein DBPE occur in the $\left(t_{H}, t_{L}\right)$-space, where $\bar{\lambda} \equiv$ $\min \left[\Lambda\left(t_{H}, t_{L}\right), 1\right]$ denotes the upper bound on the values of the prior $\lambda$ that yield a DPBE. In the inner-most "lens" (the region bounded by the $45^{\circ}-$ line $t_{L}=t_{H}$ and the curve labeled $\bar{\lambda}=1$ ), all combinations of $t_{L^{-}}$and $t_{H^{-}}$-values result in DPBE for all possible prior probabilities $(\lambda)$ that a partner's talent is $t_{\mathrm{H}}$, as Proposition 4 indicates. Along the curve labeled $\bar{\lambda}=0.5$ the equilibrium is a DPBE if the prior probability that a partner is an H-type is less than 0.5 , but it is an NPBE should $\lambda$ be at least 0.5 . Finally, a yet lower curve labeled $\bar{\lambda}=0.25$ is displayed, which contains combinations of $\mathrm{t}_{\mathrm{L}}$ - and $\mathrm{t}_{\mathrm{H}}$-values such that if $\lambda<0.25$ the SSPBE are distortionary while if $\lambda \geq 0.25$, the SSPBE are non-distortionary. The Figure reflects the previously-noted monotonicity of $\Lambda\left(t_{H}, t_{L}\right)$ in $t_{L}$ : for a fixed value of $t_{H}$, increasing $t_{L}$ is associated with an increase in the set of $\lambda$-values for which the SSPBE is distortionary (i.e, $\left(t_{H}, t_{L}\right)$ "grows" as $t_{L}$ increases), until we reach the curve labeled $\bar{\lambda}=1$, beyond which only DPBE exist. Alternatively put, $\gamma\left(t_{H}, t_{L}\right)$ gets "crowded out" as $t_{L}$ 


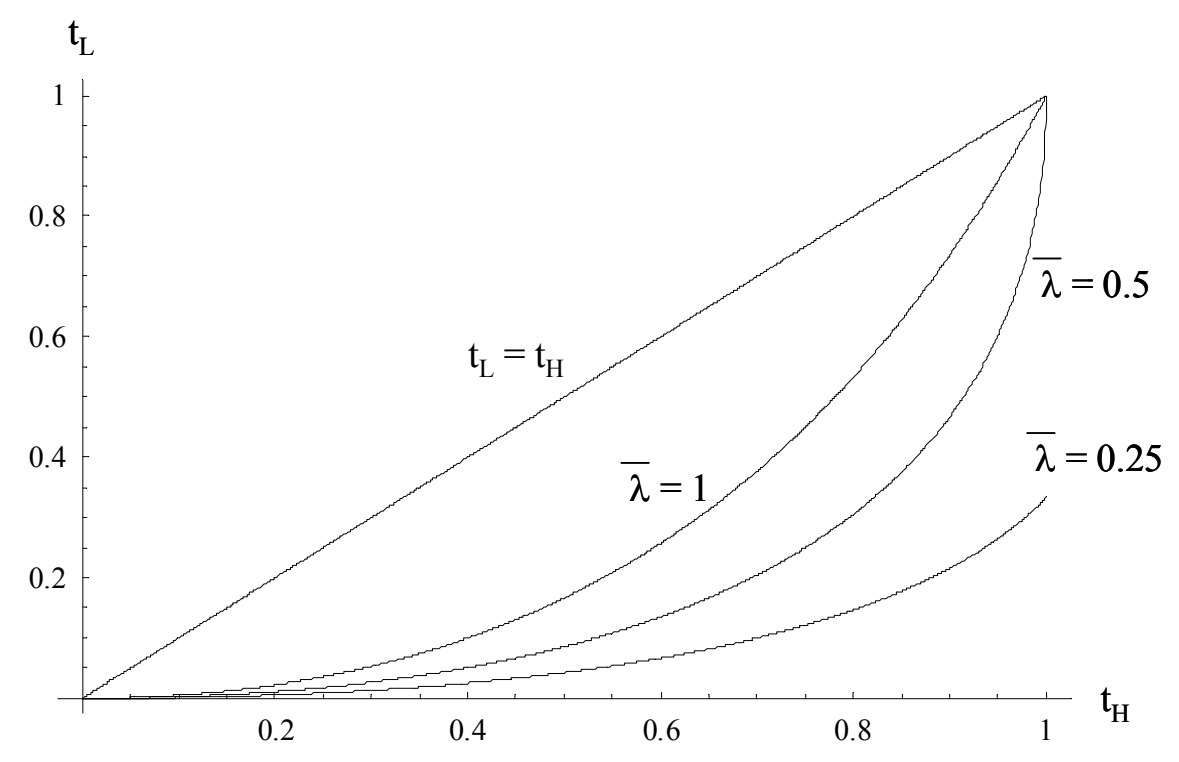

Figure 1: Regions guaranteeing DPBEs when $\lambda \epsilon(0, \bar{\lambda})$

increases (given $t_{H}$ ); this property will be employed in the numerical analysis in the next section.

Intuitively, what Figure 1 illustrates is that when the high- and low-talent values are somewhat close, the high-type will need to distort in order to separate from the low-type; thus the equilibrium is a DPBE. However, when these two values are sufficiently far apart, and the prior probability that a partner is an H-type is sufficiently high, then the equilibrium of interest will be an NPBE.

Most remarkably, the inner-most lens contains points at which the DPBE yields higher payoffs to the partners, and higher project value to the buyer, than does the corresponding completeinformation equilibrium: private information yields a Pareto improvement relative to complete information. This will not be true for any points at which $\lambda$-values exist such that the equilibrium is an NPBE (that is, at any points $\left(t_{H}, t_{L}\right)$ at which $\uparrow\left(t_{H}, t_{L}\right)$ is non-empty). Unfortunately, it is not possible to fully characterize these results analytically, but we will explore them numerically in the 
next section.

3. Comparing Equilibrium Results under Complete Information and Incomplete Information In this section we use both analytical and numerical techniques to examine the relationship between the complete-information and incomplete-information partnership equilibria.

\section{Equilibrium Effort Levels}

Recall that the complete-information ex post equilibrium effort levels, as specified in result (3) above, were denoted as $\mathrm{e}_{\mathrm{rs}}, \mathrm{r}, \mathrm{s}=\mathrm{H}, \mathrm{L}$, and that the incomplete-information equilibrium effort levels were denoted as $\mathrm{e}_{\mathrm{r}}^{0}, \mathrm{r}=\mathrm{H}, \mathrm{L}$ in the NPBE case and as $\mathrm{e}_{\mathrm{r}}^{+}, \mathrm{r}=\mathrm{H}, \mathrm{L}$ in the DPBE case. The following proposition (proved in the Appendix) provides comparisons of these equilibrium effort levels between the two information conditions.

Proposition 5. Comparison of equilibrium effort levels, with $0<\mathrm{t}_{\mathrm{L}}<\mathrm{t}_{\mathrm{H}}<1$.

(i) At any $\left(t_{H}, t_{L}\right), e_{H H}>e_{H L}>e_{L H}>e_{L L}$;

(ii) At any $\left(\mathrm{t}_{\mathrm{H}}, \mathrm{t}_{\mathrm{L}}\right)$ such that $\eta\left(\mathrm{t}_{\mathrm{H}}, \mathrm{t}_{\mathrm{L}}\right)$ is non-empty, $\mathrm{e}_{\mathrm{HH}}>\mathrm{e}_{\mathrm{H}}^{0}>\mathrm{e}_{\mathrm{HL}}$ for all $\lambda \in \eta\left(\mathrm{t}_{\mathrm{H}}, \mathrm{t}_{\mathrm{L}}\right)$;

(iii) At any $\left(t_{H}, t_{L}\right)$ such that $\eta\left(t_{H}, t_{L}\right)$ is non-empty, $e_{L}^{0}>e_{L L}$ for all $\lambda \in \eta\left(t_{H}, t_{L}\right)$;

(iv) At any $\left(t_{H}, t_{L}\right)$ such that $\eta\left(t_{H}, t_{L}\right)$ is non-empty, and for all $\lambda \in \eta\left(t_{H}, t_{L}\right)$,

$$
\mathrm{e}_{\mathrm{L}}^{0}(>=<) \mathrm{e}_{\mathrm{LH}} \text { as } \lambda(>=<) 1 /\left(1+\mathrm{t}_{\mathrm{H}}\right)
$$

(v) At any $\left(\mathrm{t}_{\mathrm{H}}, \mathrm{t}_{\mathrm{L}}\right)$ such that $\Lambda\left(\mathrm{t}_{\mathrm{H}}, \mathrm{t}_{\mathrm{L}}\right)>1, \lim _{\lambda \rightarrow 1} \mathrm{e}_{\mathrm{H}}^{+}>\mathrm{e}_{\mathrm{HH}}$;

(vi) At any $\left(t_{H}, t_{L}\right)$ such that $\&\left(t_{H}, t_{L}\right)$ is non-empty, $e_{L}^{+}>e_{L L}$ for all $\lambda \in \&\left(t_{H}, t_{L}\right)$;

(vii) At any $\left(t_{H}, t_{L}\right)$ such that $\Lambda\left(t_{H}, t_{L}\right)>1, \lim _{\lambda \rightarrow 1} e_{L}^{+}>e_{L H}$.

Proposition 5 provides a number of results. As indicated in part (i), the completeinformation equilibrium effort levels are always ordered as intuition would suggest: not only does 
an improvement in a partner's type increase the equilibrium effort for either partner (as pointed out below equation (3) earlier), effort is also increasing as one might expect in regards to the cross terms (that is, $\mathrm{e}_{\mathrm{HL}}>\mathrm{e}_{\mathrm{LH}}$ ). The next three parts (part (ii) through part (iv)) concern comparisons between the complete information equilibrium effort levels and those in an NPBE. These results are followed by the comparisons between complete information effort levels and those in a DPBE in parts (v) through (vii).

Consider the results concerning NPBE. While there are portions of the parameter space wherein the L-type's effort is higher under incomplete information than the relevant comparison effort level under complete information, notice that the H-type's effort level in an NPBE never exceeds $\mathrm{e}_{\mathrm{HH}}$. This contrasts with the H-type results in the inner-most lens of Figure 1 (wherein all equilibria are DPBE). In that portion of the parameter space, part (v) of Proposition 5 indicates that if the prior probability on an $\mathrm{H}$-type is high enough, then incomplete information results in a higher effort level for type $\mathrm{H}$ than would obtain under complete information $\left(\lim _{\lambda \rightarrow 1} \mathrm{e}_{\mathrm{H}}^{+}>\mathrm{e}_{\mathrm{HH}}\right.$, and due to part (i), $\lim _{\lambda \rightarrow 1} e_{\mathrm{H}}^{+}>e_{\mathrm{HL}}$ ). This upward-distortion of effort under incomplete information is also true in the same portion of the parameter space for the L-type. Thus, when $\lambda$ is high enough, there are always DPBE (i.e., when $\Lambda\left(t_{H}, t_{L}\right)>1$ ) wherein the effort levels for both types will be higher under incomplete information than under complete information.

\section{Equilibrium Payoff Levels}

These results suggest that private information may increase ex ante expected payoffs, at least in some portion of the parameter space. This is indeed true, but we have found it impossible to provide a complete characterization of the relevant region. Recall the definitions of the ex ante equilibrium expected payoff under incomplete information (see (10) above), $\mathrm{U}^{\mathrm{II}}$, and the ex ante 
expected equilibrium payoff under complete information (see (6) above), $\mathrm{U}^{\mathrm{CI}}$. It is straightforward to show that $\lim _{\lambda-0} \mathrm{U}^{\mathrm{II}}=\mathrm{U}^{\mathrm{CI}}$.

However, as an example, when $\left(t_{H}, t_{L}\right)=(0.75,0.60)$, then $\Lambda\left(t_{H}, t_{L}\right)=1.92593$. Thus, the point $\left(t_{H}, t_{L}\right)=(0.75,0.60)$ is in the inner-most lens in Figure 1. A graph of the difference $U^{I I}-U^{C I}$ is shown in Figure 2 below. Here, $\mathrm{U}^{\mathrm{II}}>\mathrm{U}^{\mathrm{Cl}}$ for all values of $\lambda>0$. Therefore, at this particular point (and, clearly, in a neighborhood of this point), private information is Pareto-improving, for all possible priors, in comparison with complete information.

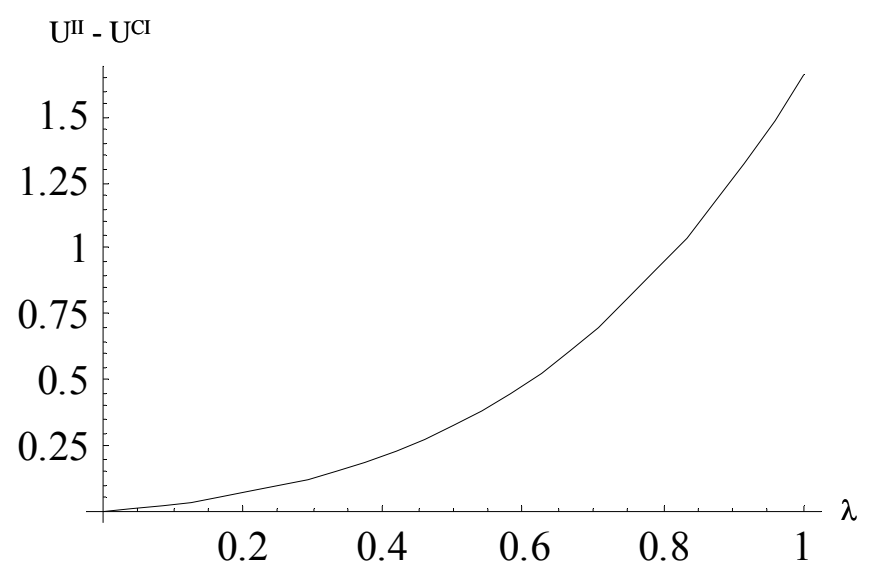

Figure 2: The Gain from Private Information at $\left(t_{H}, t_{L}\right)=(0.75,0.60)$

This does not hold for all points in the inner-most lens. For example, when $\left(t_{H}, t_{L}\right)=(0.75$, $0.50)$, then $\Lambda\left(t_{H}, t_{L}\right)=1.2$; thus, this point is also in the inner-most lens in Figure 1. However, as Figure 3 shows, $\mathrm{U}^{\mathrm{II}}>\mathrm{U}^{\mathrm{CI}}$ only for sufficiently high values of $\lambda$ (here, approximately for $\lambda>0.63$ ). Therefore, at some points in the inner-most lens, while not all priors lead to the Pareto-superiority of incomplete information, an open dense set of priors will (those with high enough values of $\lambda$ ). So, two questions arise. First, what is the sub-region wherein $\mathrm{U}^{\mathrm{II}}>\mathrm{U}^{\mathrm{CI}}$ for all values of $\lambda$, and what happens in the rest of the parameter space? We address the second issue first: a numerical 


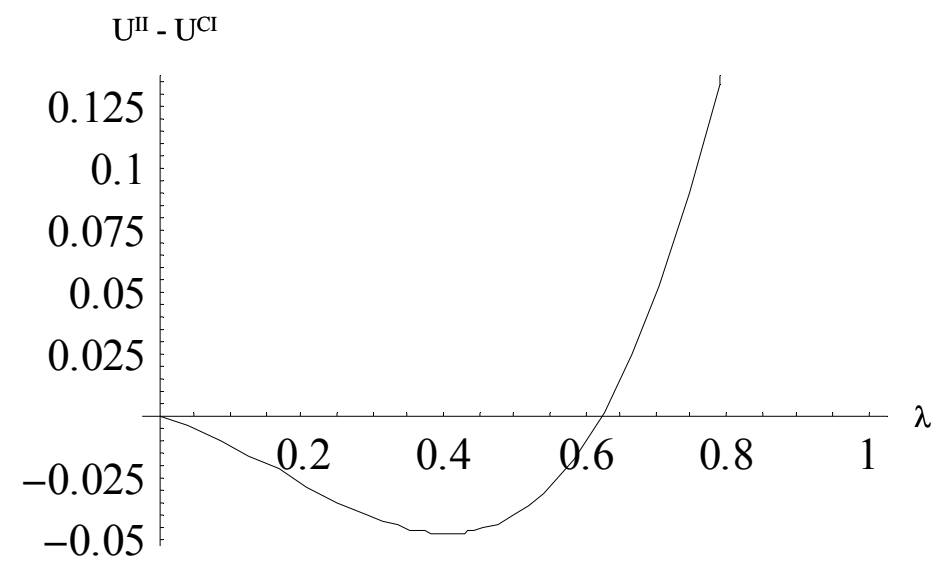

Figure 3: The Gain/Loss from Private Information at $\left(t_{\mathrm{H}}, \mathrm{t}_{\mathrm{L}}\right)=(0.75,0.50)$

screen of the parameter space outside of the inner-most lens in Figure 1 (that is, the region wherein $\eta\left(t_{H}, t_{L}\right)$ is non-empty at each point), shows that $\mathrm{U}^{\mathrm{II}}<\mathrm{U}^{\mathrm{CI}}$ : incomplete information is welfarediminishing for all $\lambda>0$. These results, and a similar exploration of the lens generated by the curve $\bar{\lambda}$ $=1$, yields Figure 4 below.

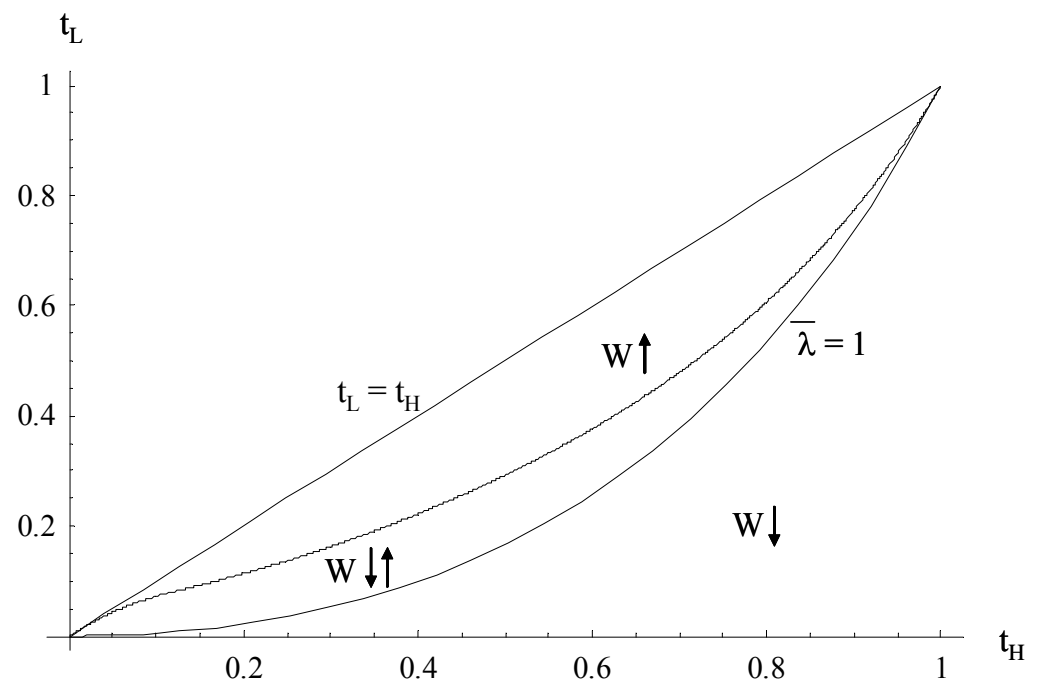

Figure 4: Numerical analysis of the effect of private information on welfare 
In Figure 4 the region labeled "W $\mathrm{W}$ " contains those $\left(\mathrm{t}_{\mathrm{H}}, \mathrm{t}_{\mathrm{L}}\right)$-pairs wherein the incompleteinformation (DBPE) payoffs always exceed the complete-information payoffs: $\mathrm{U}^{\mathrm{II}}>\mathrm{U}^{\mathrm{CI}}$ for all possible $\lambda \in(0,1)$. The region labeled labeled "W $\downarrow$ " (all of which lies outside of the inner-most lens) contains those $\left(t_{H}, t_{L}\right)$-pairs wherein the incomplete-information (DBPE and NPBE) payoffs are always less than those of the complete information equilibrium: $\mathrm{U}^{\mathrm{II}}<\mathrm{U}^{\mathrm{CI}}$ for all possible $\lambda>0$. Finally, the sub-region inside the inner-most lens which is labeled " $W \downarrow \uparrow$ " contains those $\left(t_{H}, t_{L}\right)$ pairs wherein the result of comparing the incomplete-information (DBPE) payoffs and the completeinformation payoffs depends upon the prior in question: a sufficiently high prior on the H-type results in $\mathrm{U}^{\mathrm{II}}>\mathrm{U}^{\mathrm{CI}}$. In other words, points in this region generate graphs similar to Figure 3 above.

Thus, the numerical analysis suggests the following conjecture comparing the ex ante expected payoffs (recall that, by direct computation, we know that there are $\left(t_{H}, t_{L}\right)$-pairs such that $\mathrm{U}^{\mathrm{II}}>\mathrm{U}^{\mathrm{CI}}$ for all possible values of $\lambda$ ).

$\underline{\text { Conjecture based on numerical analysis. }}$

(i) A necessary, but not sufficient, condition for $\mathrm{U}^{\mathrm{II}}>\mathrm{U}^{\mathrm{CI}}$ for all possible prior probabilities of an $\mathrm{H}$-type is that $\Lambda\left(\mathrm{t}_{\mathrm{H}}, \mathrm{t}_{\mathrm{L}}\right)>1$;

(ii) A necessary and sufficient condition for $\mathrm{U}^{\mathrm{II}}>\mathrm{U}^{\mathrm{CI}}$ for some $\lambda>0$ is that $\Lambda\left(\mathrm{t}_{\mathrm{H}}, \mathrm{t}_{\mathrm{L}}\right)>1$.

Comparison under Incomplete Information of the Two-Partner Model with a Sole Producer

We take a moment to compare the two-partner model to one wherein there is a single worker as producer in order to illustrate the critical role that strategic interaction plays in the foregoing results. In the case of incomplete information, the worker's payoff is:

$$
\mathrm{u}(\mathrm{e}, \mathrm{t}, \tilde{\mathrm{t}}) \equiv(\widetilde{\mathrm{t}}+\mathrm{e})-(\mathrm{e})^{2} /(4 \mathrm{t})
$$


where the true type $t$ and the perceived type $\tilde{t}$ need not be the same. The incentive compatibility constraints now become, for the H- and L-types, respectively:

$$
\left(\mathrm{t}_{\mathrm{H}}+\mathrm{e}_{\mathrm{H}}\right)-\left(1 / 4 \mathrm{t}_{\mathrm{H}}\right)\left(\mathrm{e}_{\mathrm{H}}\right)^{2} \geq\left(\mathrm{t}_{\mathrm{L}}+2 \mathrm{t}_{\mathrm{H}}\right)-\left(1 / 4 \mathrm{t}_{\mathrm{H}}\right)\left(2 \mathrm{t}_{\mathrm{H}}\right)^{2}
$$

and:

$$
\left(t_{L}+2 t_{L}\right)-\left(1 / 4 t_{L}\right)\left(2 t_{L}\right)^{2} \geq\left(t_{H}+e_{H}\right)-\left(1 / 4 t_{L}\right)\left(e_{H}\right)^{2}
$$

The details of the analysis are provided in the Supplementary Appendix where we show that the Htype's separating equilibrium effort level is given by $\mathrm{e}_{\mathrm{H}}^{*}=2 \mathrm{t}_{\mathrm{H}}$ if $\mathrm{t}_{\mathrm{L}} \leq \mathrm{t}_{\mathrm{H}} / 2$ and $\mathrm{e}_{\mathrm{H}}^{*}=2 \mathrm{t}_{\mathrm{L}}+2\left[\mathrm{t}_{\mathrm{L}}\left(\mathrm{t}_{\mathrm{H}}-\mathrm{t}_{\mathrm{L}}\right)\right]^{1 / 2}$ if $t_{L}>t_{H} / 2$. Note that $2 t_{L}+2\left[t_{L}\left(t_{H}-t_{L}\right)\right]^{1 / 2}>2 t_{H}$, so that when $t_{L}>t_{H} / 2$, the equilibrium requires the H-type to distort effort to a level in excess of the complete-information level, which means that the H-type chooses an effort level where profits for such a type are falling in effort. The L-type's separating equilibrium effort level is given by $\mathrm{e}_{\mathrm{L}}^{*}=2 \mathrm{t}_{\mathrm{L}}$. Further, note that the separating equilibrium effort levels depend on the support of the prior distribution, but not on $\lambda$. Moreover, when $t_{L}>t_{H} / 2$ the H-type distorts her effort level upward from her monopoly level; thus the worker's ex ante expected payoff under incomplete information is always lower than under complete information. The point is that for a sole producer, ex ante expected payoffs are never greater under incomplete information than under complete information and, for portions of the parameter space wherein a signaling distortion is part of the equilibrium (that is, where the equilibrium effort level for the $\mathrm{H}$ type exceeds the simple best-response), signaling is wasteful in the sense that the sole producer's ex ante expected payoff is lower in the incomplete-information case. This is a familiar result in single-agent signaling models, so the previous analysis shows that the introduction of strategic interaction in such settings has a significant and surprising effect: privacy can be welfare-enhancing in the strongest possible sense of being Pareto-improving. 
4. Summary of Results and Directions for Extension

The foregoing discussion can be summarized as follows. Our model is one of multi-agent simultaneous signaling; each partner is privately-informed about her own talent, but she is not informed about the other partner's talent (moreover, buyers do not know either partner's talent). Partners then simultaneously choose effort levels, followed by the sale of the product. We find a number of results. First, there are portions of the $\left(t_{H}, t_{L}, \lambda\right)$-space wherein the ex ante expected payoff to each partner is higher, and buyers are no worse off, when there is signaling than when there is complete information. This is because the value of the partners' product is increased in this region (relative to the complete-information product), so private information is Pareto-improving in this region. Second, this result occurs only in the "distortionary" equilibria (though not in any of the DPBE outside of the inner-most lens of Figure 1). Third (via the numerical analysis), this result holds for all possible priors in an open, dense set of points within the inner-most lens (the $\mathrm{W} \uparrow$-set in Figure 4). Fourth, it appears (again, via the numerical analysis), that the residual set (the $\mathrm{W} \downarrow \uparrow$-set in Figure 4) yields Pareto-improving equilibria for a subset of possible prior distributions. Fifth, the second element contributing to this Pareto-improvement (i.e., other than signaling that enhances effort) is the presence of strategic interaction: in the sole-producer model, signaling does not enhance payoffs relative to the complete-information case. Therefore, the combination of simultaneous-move strategic interaction and incomplete information can lead to conditions wherein the "problem" of adverse selection actually mitigates the problem of moral hazard.

There are a number of directions of extension. Clearly, one direction involves fleshing out 
the welfare details of incomplete-information supermodular games involving signaling ${ }^{10}$ our partnership model is an instance of such a game, but the general theory of such games is still to be developed. Another direction is to expand the type-space; if this expansion is to a continuum typespace, then one gets a differential equation of a rather complex form. The value of this extension is that it readily allows for an earlier stage wherein each partner may be able to make investments (as part of a search for a better type) that influence the prior over her talent-level (for an example of this in a products liability context with a single producer, see Daughety and Reinganum, 1995). A further direction involves exploring the effects of changing the number of partners, as well as the sharing rule. In this paper we showed that expanding the number of workers from one to two creates a region of Pareto-improving privacy. What happens as one further expands the number of partners? Alternatively, what happens if partners share unequally the project's value? For example, what are the incentive effects of shifting the design to that of a winner-take-all tournament? Do such tournaments benefit from the injection of new workers (one means for creating some degree of incomplete information about talent), or by applying existing workers in a tournament involving a new type of project (so that previously-known talents are effectively re-drawn)? A fourth direction is to expand the set of applications wherein privacy can be welfare-enhancing. All four directions of extension are topics of current research.

10 For a survey of supermodular games with simultaneous moves and incomplete information, but no signaling, see Vives (2005). 
Appendix

\section{Proof of Proposition 1.}

Overview

This proposition is proved by verifying that the strategies described in the proposition satisfy (7a)-(7d) and that they uniquely survive refinement using the Intuitive Criterion. The proof is by construction, since the strategies stated in the proposition are derived by i) requiring that (7a)-(7b) be satisfied; ii) applying the refinement argument to the set of candidate best responses to select a unique candidate pair; iii) using (7d) to solve for $\mathrm{P}^{*}$, thus generating the equilibrium strategies $\mathrm{e}_{\mathrm{H}}^{*}$ and $\mathrm{e}_{\mathrm{L}}^{*}$; and iv) associating the proper beliefs (7c) with the equilibrium strategies. Thus, the strategies described in the proposition satisfy (7a)-(7d) and they uniquely survive refinement using the Intuitive Criterion.

\section{Solution of Incentive Compatibility Constraints}

Recall the incentive constraints (7a) and (7b). Recall also that, if the incentive constraints are not tight, a partner's best response is given by $\rho_{\mathrm{L}}^{0}\left(\mathrm{P}^{*}\right)=\mathrm{t}_{\mathrm{L}} \mathrm{P}^{*}=\operatorname{argmax}_{\mathrm{e}} \mathrm{u}_{\mathrm{i}}\left(\mathrm{e}, \mathrm{t}_{\mathrm{L}}, \bullet \mid \mathrm{P}^{*}\right)$ for an $\mathrm{L}$ type and by $\rho_{\mathrm{H}}^{0}\left(\mathrm{P}^{*}\right)=\mathrm{t}_{\mathrm{H}} \mathrm{P}^{*}=\operatorname{argmax}_{\mathrm{e}} \mathrm{u}_{\mathrm{i}}\left(\mathrm{e}, \mathrm{t}_{\mathrm{H}}, \bullet \mid \mathrm{P}^{*}\right)$ for an H-type. We refer to these as the "nondistortionary best-response" functions for $\mathrm{L}$ and $\mathrm{H}$, respectively. Note two things: first, "nondistortionary" here means simply that the incentive constraints are not tight; equilibrium effort by both partners in any PBE will be distorted relative to their complete information counterparts; and second, the non-distortionary best-response functions depend only on the partner's own true type and her partner's productivity, and not on the partner's own perceived type (though the payoffs do depend on own perceived type).

Since partner i's payoff is increasing in both $\tilde{\mathfrak{t}}_{\mathrm{i}}$ and $\mathrm{t}_{\mathrm{i}}$, it is always preferable to be perceived as an $\mathrm{H}$-type given any true type, and it is always preferable to be an H-type given any perceived type. Thus, no partner would be willing to deviate from her non-distortionary best response in order to be perceived as an L-type. On the other hand, either partner would be willing to deviate from her non-distortionary best response (at least to some extent) in order to be perceived as an H-type. In a separating equilibrium, an H-type's best-response effort level $\mathrm{e}_{\mathrm{H}}$ must ensure that: a) an H-type would (at least weakly) prefer to choose $\mathrm{e}_{\mathrm{H}}$ rather than choosing her non-distortionary best response $\rho_{\mathrm{H}}^{0}\left(\mathrm{P}^{*}\right)=\mathrm{t}_{\mathrm{H}} \mathrm{P}^{*}$ and being perceived as an L-type; and $\mathrm{b}$ ) an L-type cannot do better by mimicking $\mathrm{e}_{\mathrm{H}}$ and being perceived as an $\mathrm{H}$-type than by choosing $\rho_{\mathrm{L}}^{0}\left(\mathrm{P}^{*}\right)=\mathrm{t}_{\mathrm{L}} \mathrm{P}^{*}$ and being perceived as an L-type.

Statement (a) in the preceding paragraph translates into the following inequality in $\mathrm{e}_{\mathrm{H}}$ :

$$
(1 / 2)\left(t_{\mathrm{H}}+\mathrm{e}_{\mathrm{H}}\right) \mathrm{P}^{*}-\left(1 / 4 \mathrm{t}_{\mathrm{H}}\right)\left(\mathrm{e}_{\mathrm{H}}\right)^{2} \geq(1 / 2)\left(\mathrm{t}_{\mathrm{L}}+\mathrm{t}_{\mathrm{H}} \mathrm{P}^{*}\right) \mathrm{P}^{*}-\left(1 / 4 \mathrm{t}_{\mathrm{H}}\right)\left(\mathrm{t}_{\mathrm{H}} \mathrm{P}^{*}\right)^{2},
$$

which is satisfied for all $\mathrm{e}_{\mathrm{H}}$ in the closed interval:

$$
\left[\hat{\mathrm{e}}\left(\mathrm{P}^{*}\right), \hat{\mathrm{e}}^{+}\left(\mathrm{P}^{*}\right)\right]=\left[\mathrm{t}_{\mathrm{H}} \mathrm{P}^{*}-\left[2 \mathrm{t}_{\mathrm{H}}\left(\mathrm{t}_{\mathrm{H}}-\mathrm{t}_{\mathrm{L}}\right) \mathrm{P}^{*}\right]^{1 / 2}, \mathrm{t}_{\mathrm{H}} \mathrm{P}^{*}+\left[2 \mathrm{t}_{\mathrm{H}}\left(\mathrm{t}_{\mathrm{H}}-\mathrm{t}_{\mathrm{L}}\right) \mathrm{P}^{*}\right]^{1 / 2}\right]
$$


Statement (b) in the preceding paragraph translates into the following inequality in $\mathrm{e}_{\mathrm{H}}$ :

$$
(1 / 2)\left(t_{L}+t_{L} P^{*}\right) P^{*}-\left(1 / 4 t_{L}\right)\left(t_{L} P^{*}\right)^{2} \geq(1 / 2)\left(t_{H}+e_{H}\right) P^{*}-\left(1 / 4 t_{L}\right)\left(e_{H}\right)^{2},
$$

which is satisfied for all $\mathrm{e}_{\mathrm{H}}$ not in the open interval:

$$
\left(\tilde{\mathrm{e}}\left(\mathrm{P}^{*}\right), \tilde{\mathrm{e}}^{+}\left(\mathrm{P}^{*}\right)\right)=\left(\mathrm{t}_{\mathrm{L}} \mathrm{P}^{*}-\left[2 \mathrm{t}_{\mathrm{L}}\left(\mathrm{t}_{\mathrm{H}}-\mathrm{t}_{\mathrm{L}}\right) \mathrm{P}^{*}\right]^{1 / 2}, \mathrm{t}_{\mathrm{L}} \mathrm{P}^{*}+\left[2 \mathrm{t}_{\mathrm{L}}\left(\mathrm{t}_{\mathrm{H}}-\mathrm{t}_{\mathrm{L}}\right) \mathrm{P}^{*}\right]^{1 / 2}\right) .
$$

Thus, the following are candidates for the H-type's best response (respecting the requirement of no mimicry): $\mathrm{e}_{\mathrm{H}} \in\left[\hat{\mathrm{e}}^{-}\left(\mathrm{P}^{*}\right), \tilde{\mathrm{e}}^{-}\left(\mathrm{P}^{*}\right)\right] \cup\left[\tilde{\mathrm{e}}^{+}\left(\mathrm{P}^{*}\right), \hat{\mathrm{e}}^{+}\left(\mathrm{P}^{*}\right)\right]$. The interval $\left[\hat{\mathrm{e}}^{-}\left(\mathrm{P}^{*}\right), \tilde{\mathrm{e}}-\left(\mathrm{P}^{*}\right)\right]$ may be empty, while the interval $\left[\widetilde{\mathrm{e}}^{+}\left(\mathrm{P}^{*}\right), \hat{\mathrm{e}}^{+}\left(\mathrm{P}^{*}\right)\right]$ is always non-empty.

\section{Application of the Intuitive Criterion}

We apply the Intuitive Criterion (Cho and Kreps, 1987) at the best-response stage in order to facilitate the derivation of the equilibrium. This is valid because, given partner j's conjectured separating strategy (equilibrium or otherwise), what remains is simply a single-agent signaling game between partner i and the buyers. Moreover, if there were an SSPBE wherein the H-type partner is distorting her effort level to an extent greater than the minimum necessary to deter mimicry by her alter ego (the L-type), then the Intuitive Criterion applied at the equilibrium stage would upset it, since either H-type partner could reduce the extent of distortion and still be revealed as type $\mathrm{H}$, thus improving her payoff.

According to the Intuitive Criterion, any of the effort levels $\mathrm{e}_{\mathrm{H}} \in\left[\hat{\mathrm{e}}\left(\mathrm{P}^{*}\right), \tilde{\mathrm{e}}\left(\mathrm{P}^{*}\right)\right] \cup$ $\left[\widetilde{\mathrm{e}}^{+}\left(\mathrm{P}^{*}\right), \hat{\mathrm{e}}^{+}\left(\mathrm{P}^{*}\right)\right]$ should be attributed to the H-type (since the L-type could never gain - even if he were to be perceived as an H-type - by choosing such an effort level). Thus, the H-type simply needs to choose its preferred value of $\mathrm{e}_{\mathrm{H}}$ from within these two intervals.

First, we argue that no effort level in $\left[\hat{\mathrm{e}}^{-}\left(\mathrm{P}^{*}\right), \tilde{\mathrm{e}}^{-}\left(\mathrm{P}^{*}\right)\right]$ will be chosen by the H-type. For some parameter values, this interval is empty, and therefore irrelevant. Now suppose that this interval is nonempty; since it is entirely below the H-type's non-distortionary best-response function $\rho_{\mathrm{H}}^{0}\left(\mathrm{P}^{*}\right)$ $=\mathrm{t}_{\mathrm{H}} \mathrm{P}^{*}$, the best candidate in this interval is its highest element, $\tilde{\mathrm{e}}^{-}\left(\mathrm{P}^{*}\right)$. However, straightforward calculation shows that the H-type would prefer the effort level $\widetilde{\mathrm{e}}^{+}\left(\mathrm{P}^{*}\right)$ to the effort level $\widetilde{\mathrm{e}}^{-}\left(\mathrm{P}^{*}\right)$; that is, $\mathrm{u}_{\mathrm{i}}\left(\tilde{\mathrm{e}}^{-}\left(\mathrm{P}^{*}\right), \mathrm{t}_{\mathrm{H}}, \mathrm{t}_{\mathrm{H}} \mid \mathrm{P}^{*}\right)<\mathrm{u}_{\mathrm{i}}\left(\widetilde{\mathrm{e}}^{+}\left(\mathrm{P}^{*}\right), \mathrm{t}_{\mathrm{H}}, \mathrm{t}_{\mathrm{H}} \mid \mathrm{P}^{*}\right)$.

Thus, we can confine our search for the H-type's best-response effort level to the interval $\left[\widetilde{\mathrm{e}}^{+}\left(\mathrm{P}^{*}\right), \hat{\mathrm{e}}^{+}\left(\mathrm{P}^{*}\right)\right]$. For some parameter values, this interval lies entirely above the H-type's nondistortionary best-response function $\rho_{\mathrm{H}}^{0}\left(\mathrm{P}^{*}\right)=\mathrm{t}_{\mathrm{H}} \mathrm{P}^{*}$, and for other parameter values, $\rho_{\mathrm{H}}^{0}\left(\mathrm{P}^{*}\right)=\mathrm{t}_{\mathrm{H}} \mathrm{P}^{*}$ lies within the interval (in which case the H-type can reveal her type without distorting her best response to deter mimicry). Therefore, if $\rho_{\mathrm{H}}^{0}\left(\mathrm{P}^{*}\right) \geq \tilde{\mathrm{e}}^{+}\left(\mathrm{P}^{*}\right)$, then the $\mathrm{H}$-type's best-response function is given by $\rho_{\mathrm{H}}^{0}\left(\mathrm{P}^{*}\right)$. On the other hand, if $\rho_{\mathrm{H}}^{0}\left(\mathrm{P}^{*}\right)<\widetilde{\mathrm{e}}^{+}\left(\mathrm{P}^{*}\right)$, then the H-type will distort her effort level to the minimum extent necessary to deter mimicry by the L-type; that is, the H-type's best response will be $\rho_{\mathrm{H}}^{+}\left(\mathrm{P}^{*}\right) \equiv \tilde{\mathrm{e}}^{+}\left(\mathrm{P}^{*}\right)$; we will refer to this as the H-type's "distortionary best-response function." We conclude that the H-type's best-response effort level (written as a function of $\mathrm{P}^{*}$ ) is given by 
$\mathrm{BR}_{\mathrm{H}}\left(\mathrm{P}^{*}\right) \equiv \max \left\{\mathrm{t}_{\mathrm{H}} \mathrm{P}^{*}, \tilde{\mathrm{e}}^{+}\left(\mathrm{P}^{*}\right)\right\}$. Comparing these two functions yields the following characterization of the H-type's best-response function (which is continuous at the point of transition):

$$
\mathrm{BR}_{\mathrm{H}}\left(\mathrm{P}^{*}\right)= \begin{cases}\rho_{\mathrm{H}}^{+}\left(\mathrm{P}^{*}\right) & \text { when } \mathrm{P}^{*}<2 \mathrm{t}_{\mathrm{L}} /\left(\mathrm{t}_{\mathrm{H}}-\mathrm{t}_{\mathrm{L}}\right) \\ \rho_{\mathrm{H}}^{0}\left(\mathrm{P}^{*}\right) & \text { when } \mathrm{P}^{*} \geq 2 \mathrm{t}_{\mathrm{L}} /\left(\mathrm{t}_{\mathrm{H}}-\mathrm{t}_{\mathrm{L}}\right) .\end{cases}
$$

The L-type's best-response function is $\mathrm{BR}_{\mathrm{L}}\left(\mathrm{P}^{*}\right)=\rho_{\mathrm{L}}^{0}\left(\mathrm{P}^{*}\right)$ for all $\mathrm{P}^{*}$.

\section{Finding $P^{*}$ and Showing that it is Unique and Associating the Proper Beliefs}

In an SSPBE, each partner's expected productivity must equal that of her partner, $\mathrm{P} *$. Given the best-response functions derived above, the partner's expected productivity is given by $\varphi\left(\mathrm{P}^{*}\right) \equiv$ $\max \left\{\varphi^{+}\left(\mathrm{P}^{*}\right), \varphi^{0}\left(\mathrm{P}^{*}\right)\right\}$, where $\varphi^{+}\left(\mathrm{P}^{*}\right) \equiv \lambda\left(\mathrm{t}_{\mathrm{H}}+\rho_{\mathrm{H}}^{+}\left(\mathrm{P}^{*}\right)\right)+(1-\lambda)\left(\mathrm{t}_{\mathrm{L}}+\rho_{\mathrm{L}}^{0}\left(\mathrm{P}^{*}\right)\right)=\overline{\mathrm{t}}+\mathrm{t}_{\mathrm{L}} \mathrm{P}^{*}+\lambda\left[2 \mathrm{t}_{\mathrm{L}}\left(\mathrm{t}_{\mathrm{H}}-\right.\right.$ $\left.\left.\mathrm{t}_{\mathrm{L}}\right) \mathrm{P}^{*}\right]^{1 / 2}$ and $\varphi^{0}\left(\mathrm{P}^{*}\right) \equiv \lambda\left(\mathrm{t}_{\mathrm{H}}+\rho_{\mathrm{H}}^{0}\left(\mathrm{P}^{*}\right)\right)+(1-\lambda)\left(\mathrm{t}_{\mathrm{L}}+\rho_{\mathrm{L}}^{0}\left(\mathrm{P}^{*}\right)\right)=\overline{\mathrm{t}}+\overline{\mathrm{t}} \mathrm{P}^{*}$. Again, the transition occurs at $\mathrm{P}^{*}=2 \mathrm{t}_{\mathrm{L}} /\left(\mathrm{t}_{\mathrm{H}}-\mathrm{t}_{\mathrm{L}}\right)$, so that:

$$
\varphi\left(P^{*}\right)= \begin{cases}\bar{t}+t_{L} P^{*}+\lambda\left[2 t_{L}\left(t_{H}-t_{L}\right) P^{*}\right]^{1 / 2} & \text { when } P^{*}<2 t_{L} /\left(t_{H}-t_{L}\right) \\ \bar{t}+\bar{t} P^{*} & \text { when } P^{*} \geq 2 t_{L} /\left(t_{H}-t_{L}\right)\end{cases}
$$

Any value of $\mathrm{P}^{*}$ such that $\mathrm{P}^{*}=\varphi\left(\mathrm{P}^{*}\right)$ will generate symmetric separating $\mathrm{PBE}$ effort levels by appropriate substitution into the functions $\mathrm{BR}_{\mathrm{H}}\left(\mathrm{P}^{*}\right)$ and $\mathrm{BR}_{\mathrm{L}}\left(\mathrm{P}^{*}\right)$. We will show below that there is a unique solution to the equation $\mathrm{P}^{*}=\varphi\left(\mathrm{P}^{*}\right)$. For some parameter values, it will be given by $\mathrm{P}^{*}$ $=\varphi^{+}\left(\mathrm{P}^{*}\right)$. We will denote this solution by $\mathrm{P}^{+}$, with the implied effort levels being denoted $\mathrm{e}_{\mathrm{L}}^{+}=\mathrm{t}_{\mathrm{L}} \mathrm{P}^{+}$ and $\mathrm{e}_{\mathrm{H}}^{+}=\mathrm{t}_{\mathrm{L}} \mathrm{P}^{+}+\left[2 \mathrm{t}_{\mathrm{L}}\left(\mathrm{t}_{\mathrm{H}}-\mathrm{t}_{\mathrm{L}}\right) \mathrm{P}^{+}\right]^{1 / 2}$, and we will refer to this as a "distortionary perfect Bayesian equilibrium (DPBE)." For other parameters, the solution will be given by $\mathrm{P}^{*}=\varphi^{0}\left(\mathrm{P}^{*}\right)$. We will denote this solution by $\mathrm{P}^{0}$, with the implied effort levels being denoted $\mathrm{e}_{\mathrm{L}}^{0}=\mathrm{t}_{\mathrm{L}} \mathrm{P}^{0}$ and $\mathrm{e}_{\mathrm{H}}^{0}=\mathrm{t}_{\mathrm{H}} \mathrm{P}^{0}$, and we will refer to this as a "non-distortionary perfect Bayesian equilibrium (NPBE)."

Lemma 1. (a) There exists a unique $\mathrm{P}^{+} \in(0, \infty)$ such that $\varphi^{+}(\mathrm{P})(>=<) \mathrm{P}$ as $\mathrm{P}(<=>) \mathrm{P}^{+}$.

(b) There exists a unique $\mathrm{P}^{0} \in(0, \infty)$ such that $\varphi^{0}(\mathrm{P})(>=<) \mathrm{P}$ as $\mathrm{P}(<=>) \mathrm{P}^{0}$.

\section{Proof of Lemma 1.}

(a) Since $\varphi^{+}(0)>0$ and $\varphi^{+}(\mathrm{P})$ is a strictly increasing and concave function with $\lim _{\mathrm{P} \rightarrow \infty} \varphi^{+\prime}(\mathrm{P})$ $=\mathrm{t}_{\mathrm{L}}<1$, it follows that the function $\varphi^{+}(\mathrm{P})$ begins above the $45^{\circ}$-line and crosses it just once. (b) Since $\varphi^{0}(0)>0$ and $\varphi^{0}(\mathrm{P})$ is linear in $\mathrm{P}$ with slope $\overline{\mathrm{t}}<1$, it follows that the function $\varphi^{0}(\mathrm{P})$ begins above the $45^{\circ}$-line and crosses it just once. QED Lemma 1

The value of $\mathrm{P}^{0}$ is easily computed to be $\mathrm{P}^{0}=\overline{\mathrm{t}} /(1-\overline{\mathrm{t}})$. The computation of $\mathrm{P}^{+}$is more complicated, as it is given by $\mathrm{P}^{+}=\overline{\mathrm{t}}+\mathrm{t}_{\mathrm{L}} \mathrm{P}^{+}+\lambda\left[2 \mathrm{t}_{\mathrm{L}}\left(\mathrm{t}_{\mathrm{H}}-\mathrm{t}_{\mathrm{L}}\right) \mathrm{P}^{+}\right]^{1 / 2}$. Let $\mathrm{Y} \equiv\left[2 \mathrm{t}_{\mathrm{L}}\left(\mathrm{t}_{\mathrm{H}}-\mathrm{t}_{\mathrm{L}}\right) \mathrm{P}^{+}\right]^{1 / 2}$. Then $\mathrm{P}^{+}$ $=\overline{\mathrm{t}}+\mathrm{t}_{\mathrm{L}} \mathrm{P}^{+}+\lambda \mathrm{Y}$ and $\mathrm{P}^{+}=\mathrm{Y}^{2} / 2 \mathrm{t}_{\mathrm{L}}\left(\mathrm{t}_{\mathrm{H}}-\mathrm{t}_{\mathrm{L}}\right)$. Equating these gives a quadratic in $\mathrm{Y}$ that has one positive 
and one negative root. Since $\mathrm{Y}$ is a square root (and therefore must be positive), it is the positive root that we seek. This root is $Y=\lambda t_{L}\left(t_{H}-t_{L}\right) /\left(1-t_{L}\right)+\left\{\left[\lambda t_{L}\left(t_{H}-t_{L}\right) /\left(1-t_{L}\right)\right]^{2}+2 \overline{t t}_{L}\left(t_{H}-t_{L}\right) /(1-\right.$ $\left.\left.\mathrm{t}_{\mathrm{L}}\right)\right\}^{1 / 2}$. Substituting back into the equation $\mathrm{P}^{+}=\overline{\mathrm{t}}+\mathrm{t}_{\mathrm{L}} \mathrm{P}^{+}+\lambda \mathrm{Y}$ and solving yields the value of $\mathrm{P}^{+}$.

$\mathrm{P}^{+}=\overline{\mathrm{t}} /\left(1-\mathrm{t}_{\mathrm{L}}\right)+\left[\lambda /\left(1-\mathrm{t}_{\mathrm{L}}\right)\right]\left[\lambda \mathrm{t}_{\mathrm{L}}\left(\mathrm{t}_{\mathrm{H}}-\mathrm{t}_{\mathrm{L}}\right) /\left(1-\mathrm{t}_{\mathrm{L}}\right)+\left\{\left[\lambda \mathrm{t}_{\mathrm{L}}\left(\mathrm{t}_{\mathrm{H}}-\mathrm{t}_{\mathrm{L}}\right) /\left(1-\mathrm{t}_{\mathrm{L}}\right)\right]^{2}+2 \overline{\mathrm{t}}_{\mathrm{L}}\left(\mathrm{t}_{\mathrm{H}}-\mathrm{t}_{\mathrm{L}}\right) /\left(1-\mathrm{t}_{\mathrm{L}}\right)\right\}^{1 / 2}\right]$.

Since $\varphi\left(\mathrm{P}^{*}\right)=\max \left\{\varphi^{+}\left(\mathrm{P}^{*}\right), \varphi^{0}\left(\mathrm{P}^{*}\right)\right\}$, the values $\mathrm{P}^{+}$and $\mathrm{P}^{0}$ provide candidates for equilibrium values of $\mathrm{P}^{*}$. However, only one of these will actually provide an equilibrium value of $\mathrm{P}^{*}$, depending on the prevailing parameters.

Lemma 2. There exists a unique $\mathrm{P}^{*} \in(0, \infty)$ such that $\varphi(\mathrm{P})(>=<) \mathrm{P}$ as $\mathrm{P}(<=>) \mathrm{P}^{*}$.

(a) If $\mathrm{P}^{0}=\overline{\mathrm{t}} /(1-\overline{\mathrm{t}})<2 \mathrm{t}_{\mathrm{L}} /\left(\mathrm{t}_{\mathrm{H}}-\mathrm{t}_{\mathrm{L}}\right)$, then $\mathrm{P}^{*}=\mathrm{P}^{+}$, and the SSPBE is distortionary.

(b) If $\mathrm{P}^{0}=\overline{\mathrm{t}} /(1-\overline{\mathrm{t}})>2 \mathrm{t}_{\mathrm{L}} /\left(\mathrm{t}_{\mathrm{H}}-\mathrm{t}_{\mathrm{L}}\right)$, then $\mathrm{P}^{*}=\mathrm{P}^{0}$, and the SSPBE is non-distortionary.

(c) If $\mathrm{P}^{0}=\overline{\mathrm{t}} /(1-\overline{\mathrm{t}})=2 \mathrm{t}_{\mathrm{L}} /\left(\mathrm{t}_{\mathrm{H}}-\mathrm{t}_{\mathrm{L}}\right)$, then $\mathrm{P}^{*}=\mathrm{P}^{0}=\mathrm{P}^{+}$, and the SSPBE is non-distortionary since the distortion associated with $\mathrm{P}^{+}$is zero.

Proof of Lemma 2. First note that $\varphi(0)=\varphi^{+}(0)=\varphi^{0}(0)>0$, so $\mathrm{P}=0$ is never an equilibrium value.

The remainder of the proof considers $\mathrm{P} \in(0, \infty)$.

(a) Suppose that $\mathrm{P}^{0}=\overline{\mathrm{t}} /(1-\overline{\mathrm{t}})<2 \mathrm{t}_{\mathrm{L}} /\left(\mathrm{t}_{\mathrm{H}}-\mathrm{t}_{\mathrm{L}}\right)$. For all $\mathrm{P} \in\left(0, \mathrm{P}^{0}\right), \varphi(\mathrm{P})=\varphi^{+}(\mathrm{P})>\varphi^{0}(\mathrm{P})>\mathrm{P}$. Moreover, $\varphi\left(\mathrm{P}^{0}\right)=\varphi^{+}\left(\mathrm{P}^{0}\right)>\varphi^{0}\left(\mathrm{P}^{0}\right)=\mathrm{P}^{0}$. For all $\mathrm{P} \in\left(\mathrm{P}^{0}, 2 \mathrm{t}_{\mathrm{L}} /\left(\mathrm{t}_{\mathrm{H}}-\mathrm{t}_{\mathrm{L}}\right)\right), \varphi(\mathrm{P})=\varphi^{+}(\mathrm{P})>\varphi^{0}(\mathrm{P})$ but $\varphi^{0}(\mathrm{P})<\mathrm{P}$. At $\mathrm{P}=2 \mathrm{t}_{\mathrm{L}} /\left(\mathrm{t}_{\mathrm{H}}-\mathrm{t}_{\mathrm{L}}\right), \varphi(\mathrm{P})=\varphi^{+}(\mathrm{P})=\varphi^{0}(\mathrm{P})<\mathrm{P}$. Since we have shown that $\varphi\left(\mathrm{P}^{0}\right)>$ $\mathrm{P}^{0}$ and $\varphi\left(2 \mathrm{t}_{\mathrm{L}} /\left(\mathrm{t}_{\mathrm{H}}-\mathrm{t}_{\mathrm{L}}\right)\right)<2 \mathrm{t}_{\mathrm{L}} /\left(\mathrm{t}_{\mathrm{H}}-\mathrm{t}_{\mathrm{L}}\right)$, and since $\varphi(\bullet)$ is monotonically increasing, it follows that there exists a unique $\mathrm{P}^{*} \in\left(\mathrm{P}^{0}, 2 \mathrm{t}_{\mathrm{L}} /\left(\mathrm{t}_{\mathrm{H}}-\mathrm{t}_{\mathrm{L}}\right)\right)$ such that $\varphi(\mathrm{P})(>=<) \mathrm{P}$ as $\mathrm{P}(<=>) \mathrm{P}^{*}$. Since $\varphi(\mathrm{P})=\varphi^{+}(\mathrm{P})$ on this interval, $\mathrm{P}^{*}$ is given by $\mathrm{P}^{+}$. Finally, for all $\mathrm{P} \in\left(2 \mathrm{t}_{\mathrm{L}} /\left(\mathrm{t}_{\mathrm{H}}-\mathrm{t}_{\mathrm{L}}\right), \infty\right), \varphi(\mathrm{P})=$ $\varphi^{0}(\mathrm{P})<\mathrm{P}$. Thus, there is only one value of $\mathrm{P}^{*}$ for which $\varphi\left(\mathrm{P}^{*}\right)=\mathrm{P}^{*}$, and that is $\mathrm{P}^{*}=\mathrm{P}^{+}$.

(b) Suppose that $\mathrm{P}^{0}=\overline{\mathrm{t}} /(1-\overline{\mathrm{t}})>2 \mathrm{t}_{\mathrm{L}} /\left(\mathrm{t}_{\mathrm{H}}-\mathrm{t}_{\mathrm{L}}\right)$. For all $\mathrm{P} \in\left(0,2 \mathrm{t}_{\mathrm{L}} /\left(\mathrm{t}_{\mathrm{H}}-\mathrm{t}_{\mathrm{L}}\right)\right), \varphi(P)=\varphi^{+}(P)>\varphi^{0}(P)$ $>\mathrm{P}$. For all $\mathrm{P} \in\left[2 \mathrm{t}_{\mathrm{L}} /\left(\mathrm{t}_{\mathrm{H}}-\mathrm{t}_{\mathrm{L}}\right), \infty\right), \varphi(\mathrm{P})=\varphi^{0}(\mathrm{P})(>=<) \mathrm{P}$ as $\mathrm{P}(<=>) \mathrm{P}^{0}$. Thus, there is only one value of $\mathrm{P}^{*}$ for which $\varphi\left(\mathrm{P}^{*}\right)=\mathrm{P}^{*}$, and that is $\mathrm{P}^{*}=\mathrm{P}^{0}$.

(c) Suppose that $\mathrm{P}^{0}=\overline{\mathrm{t}} /(1-\overline{\mathrm{t}})=2 \mathrm{t}_{\mathrm{L}} /\left(\mathrm{t}_{\mathrm{H}}-\mathrm{t}_{\mathrm{L}}\right)$. Then it is straightforward to show that $\mathrm{P}^{+}=\mathrm{P}^{0}$. For $\mathrm{P} \in\left(0, \mathrm{P}^{0}\right), \varphi(\mathrm{P})=\varphi^{+}(\mathrm{P})>\mathrm{P}$; at $\mathrm{P}=\mathrm{P}^{0}, \varphi\left(\mathrm{P}^{0}\right)=\varphi^{+}\left(\mathrm{P}^{0}\right)=\varphi^{0}\left(\mathrm{P}^{0}\right)=\mathrm{P}^{0}$; and for $\mathrm{P} \in\left(\mathrm{P}^{0}, \infty\right)$, $\varphi(\mathrm{P})=\varphi^{0}(\mathrm{P})<\mathrm{P}$. Thus, there is only one value of $\mathrm{P}^{*}$ for which $\varphi\left(\mathrm{P}^{*}\right)=\mathrm{P}^{*}$, and that is $\mathrm{P}^{*}$ $=\mathrm{P}^{0}$. QED Lemma 2

Finally, the SSPBE effort levels depend on the parameter regime. A DPBE arises if $\mathrm{P}^{0}=$ $\overline{\mathrm{t}} /(1-\overline{\mathrm{t}})<2 \mathrm{t}_{\mathrm{L}} /\left(\mathrm{t}_{\mathrm{H}}-\mathrm{t}_{\mathrm{L}}\right)$. In this case, $\mathrm{P}^{*}=\mathrm{P}^{+}$and the effort levels are $\mathrm{e}_{\mathrm{H}}^{*}=\mathrm{e}_{\mathrm{H}}^{+}=\mathrm{t}_{\mathrm{L}} \mathrm{P}^{+}+\left[2 \mathrm{t}_{\mathrm{L}}\left(\mathrm{t}_{\mathrm{H}}-\mathrm{t}_{\mathrm{L}}\right) \mathrm{P}^{+}\right]^{1 / 2}$ and $\mathrm{e}_{\mathrm{L}}^{*}=\mathrm{e}_{\mathrm{L}}^{+}=\mathrm{t}_{\mathrm{L}} \mathrm{P}^{+}$. An NPBE arises if $\mathrm{P}^{0}=\overline{\mathrm{t}} /(1-\overline{\mathrm{t}}) \geq 2 \mathrm{t}_{\mathrm{L}} /\left(\mathrm{t}_{\mathrm{H}}-\mathrm{t}_{\mathrm{L}}\right)$. In this case, $\mathrm{P}^{*}=\mathrm{P}^{0}$ and the effort levels are $\mathrm{e}_{\mathrm{H}}^{*}=\mathrm{e}_{\mathrm{H}}^{0}=\mathrm{t}_{\mathrm{H}} \mathrm{P}^{0}$ and $\mathrm{e}_{\mathrm{L}}^{*}=\mathrm{e}_{\mathrm{L}}^{0}=\mathrm{t}_{\mathrm{L}} \mathrm{P}^{0}$. The beliefs that support the equilibrium are as follows: if $\mathrm{e} \geq \mathrm{e}_{\mathrm{H}}^{*}$, then the buyers infer that the partner is an $\mathrm{H}$-type; and if $\mathrm{e}<\mathrm{e}_{\mathrm{H}}^{*}$, then the buyers infer that the partner is an L-type.

QED Proposition 1. 
$\underline{\text { Statement of Interim and Ex Ante Expected Payoffs under Incomplete Information }}$

Interim equilibrium payoffs are:

$$
\begin{aligned}
\mathrm{U}_{\mathrm{H}}^{\mathrm{II}}= & \lambda \mathrm{u}_{\mathrm{i}}\left(\mathrm{e}_{\mathrm{H}}^{*}, \mathrm{t}_{\mathrm{H}}, \mathrm{t}_{\mathrm{H}} \mid \mathrm{e}_{\mathrm{H}}^{*}, \mathrm{t}_{\mathrm{H}}\right)+(1-\lambda) \mathrm{u}_{\mathrm{i}}\left(\mathrm{e}_{\mathrm{H}}^{*}, \mathrm{t}_{\mathrm{H}}, \mathrm{t}_{\mathrm{H}} \mid \mathrm{e}_{\mathrm{L}}^{*}, \mathrm{t}_{\mathrm{L}}\right) \\
& =\mathrm{u}_{\mathrm{i}}\left(\mathrm{e}_{\mathrm{H}}^{*}, \mathrm{t}_{\mathrm{H}}, \mathrm{t}_{\mathrm{H}} \mid \mathrm{P}^{*}\right) \\
& =\left(\mathrm{t}_{\mathrm{H}}+\mathrm{e}_{\mathrm{H}}^{*}\right) \mathrm{P}^{*}-\left(\mathrm{e}_{\mathrm{H}}^{*}\right)^{2} /\left(4 \mathrm{t}_{\mathrm{H}}\right),
\end{aligned}
$$

and

$$
\begin{aligned}
\mathrm{U}_{\mathrm{L}}^{\mathrm{II}}= & \lambda \mathrm{u}_{\mathrm{i}}\left(\mathrm{e}_{\mathrm{L}}^{*}, \mathrm{t}_{\mathrm{L}}, \mathrm{t}_{\mathrm{L}} \mid \mathrm{e}_{\mathrm{H}}^{*}, \mathrm{t}_{\mathrm{H}}\right)+(1-\lambda) \mathrm{u}_{\mathrm{i}}\left(\mathrm{e}_{\mathrm{L}}^{*}, \mathrm{t}_{\mathrm{L}}, \mathrm{t}_{\mathrm{L}} \mid \mathrm{e}_{\mathrm{L}}^{*}, \mathrm{t}_{\mathrm{L}}\right) \\
& =\mathrm{u}_{\mathrm{i}}\left(\mathrm{e}_{\mathrm{L}}^{*}, \mathrm{t}_{\mathrm{L}}, \mathrm{t}_{\mathrm{L}} \mid \mathrm{P}^{*}\right) \\
& =\left(\mathrm{t}_{\mathrm{L}}+\mathrm{e}_{\mathrm{L}}^{*}\right) \mathrm{P}^{*}-\left(\mathrm{e}_{\mathrm{L}}^{*}\right)^{2} /\left(4 \mathrm{t}_{\mathrm{L}}\right) .
\end{aligned}
$$

If $\bar{t} /(1-\bar{t})<2 t_{L} /\left(t_{H}-t_{L}\right)$, then $P^{*}=P^{+}=\bar{t} /\left(1-t_{L}\right)+\lambda /\left(1-t_{L}\right)\left[\lambda t_{L}\left(t_{H}-t_{L}\right) /\left(1-t_{L}\right)+\left\{\left[\lambda t_{L}\left(t_{H}-t_{L}\right) /(1-\right.\right.\right.$ $\left.\left.\left.\left.\mathrm{t}_{\mathrm{L}}\right)\right]^{2}+2 \mathrm{tt}_{\mathrm{L}}\left(\mathrm{t}_{\mathrm{H}}-\mathrm{t}_{\mathrm{L}}\right) /\left(1-\mathrm{t}_{\mathrm{L}}\right)\right\}_{-}^{1 / 2}\right], \mathrm{e}_{\mathrm{H}_{-}}^{*}=\mathrm{e}_{\mathrm{H}}^{+}=\mathrm{t}_{\mathrm{L}} \mathrm{P}^{+}+\left[2 \mathrm{t}_{\mathrm{L}}\left(\mathrm{t}_{\mathrm{H}}-\mathrm{t}_{\mathrm{L}}\right) \mathrm{P}^{+}\right]^{1 / 2}$ and $\mathrm{e}_{\mathrm{L}}^{*}=\mathrm{e}_{\mathrm{L}}^{+}=\mathrm{t}_{\mathrm{L}} \mathrm{P}^{+}$. If $\overline{\mathrm{t}} /(1-\overline{\mathrm{t}}) \geq$ $2 \mathrm{t}_{\mathrm{L}} /\left(\mathrm{t}_{\mathrm{H}}-\mathrm{t}_{\mathrm{L}}\right)$, then $\mathrm{P}^{*}=\mathrm{P}^{0}=\overline{\mathrm{t}} /(1-\overline{\mathrm{t}}), \mathrm{e}_{\mathrm{H}}^{*}=\mathrm{e}_{\mathrm{H}}^{0}=\mathrm{t}_{\mathrm{H}} \mathrm{P}^{0}$ and $\mathrm{e}_{\mathrm{L}}^{*}=\mathrm{e}_{\mathrm{L}}^{0}=\mathrm{t}_{\mathrm{L}} \mathrm{P}^{0}$. Thus, the ex ante expected payoff to a partner under incomplete information, denoted as $\mathrm{U}^{\mathrm{II}}$, is:

$$
\mathrm{U}^{\mathrm{II}} \equiv \lambda\left[\left(\mathrm{t}_{\mathrm{H}}+\mathrm{e}_{\mathrm{H}}^{*}\right) \mathrm{P}^{*}-\left(\mathrm{e}_{\mathrm{H}}^{*}\right)^{2} /\left(4 \mathrm{t}_{\mathrm{H}}\right)\right]+(1-\lambda)\left[\left(\mathrm{t}_{\mathrm{L}}+\mathrm{e}_{\mathrm{L}}^{*}\right) \mathrm{P}^{*}-\left(\mathrm{e}_{\mathrm{L}}^{*}\right)^{2} /\left(4 \mathrm{t}_{\mathrm{L}}\right)\right] .
$$

Proof of Proposition 3.

i) $\mathrm{U}_{\mathrm{H}}^{\mathrm{II}} \geq \max _{\mathrm{e}}\left(\mathrm{t}_{\mathrm{L}}+\mathrm{e}\right) \mathrm{P} * / 2-(\mathrm{e})^{2} /\left(4 \mathrm{t}_{\mathrm{H}}\right)>\max _{\mathrm{e}}\left(\mathrm{t}_{\mathrm{L}}+\mathrm{e}\right) \mathrm{P} * / 2-(\mathrm{e})^{2} /\left(4 \mathrm{t}_{\mathrm{L}}\right)=\mathrm{U}_{\mathrm{L}}^{\mathrm{II}}$, where the first (weak) inequality follows from the incentive compatibility constraint (6a); the second (strong) inequality follows from the fact that $t_{L}<t_{H}$; and the equality follows from the fact that the L-type plays according to her non-distortionary best-response function.

ii) First consider $\mathrm{U}_{\mathrm{L}}^{\mathrm{II}}=\max _{\mathrm{e}}\left(\mathrm{t}_{\mathrm{L}}+\mathrm{e}\right) \mathrm{P}^{*} / 2-(\mathrm{e})^{2} /\left(4 \mathrm{t}_{\mathrm{L}}\right)$, where $\mathrm{P}^{*}=\mathrm{P}^{0}$ or $\mathrm{P}^{*}=\mathrm{P}^{+}$as appropriate. Note that both $\mathrm{P}^{0}$ and $\mathrm{P}^{+}$are increasing functions of $\lambda$. Since the L-type always plays according to her non-distortionary best-response function, it follows from the envelope theorem that $\partial \mathrm{U}_{\mathrm{L}}^{\mathrm{II}} / \partial \lambda=\left(\mathrm{t}_{\mathrm{L}}+\mathrm{e}_{\mathrm{L}}^{*}\right)(\partial \mathrm{P} * / \partial \lambda) / 2>0$. Now consider $\mathrm{U}_{\mathrm{H}}^{\mathrm{II}}$; the same envelope theorem argument applies when the SSPBE is non-distortionary since, in that case, $\mathrm{U}_{\mathrm{H}}^{\mathrm{II}}=$ $\max _{\mathrm{e}}\left(\mathrm{t}_{\mathrm{H}}+\mathrm{e}\right) \mathrm{P}^{0} / 2-(\mathrm{e})^{2} /\left(4 \mathrm{t}_{\mathrm{H}}\right)$. The argument is more complex when $\mathrm{U}_{\mathrm{H}}^{\mathrm{II}}=\left(\mathrm{t}_{\mathrm{H}}+\mathrm{e}_{\mathrm{H}}^{+}\right) \mathrm{P}^{+} / 2$ $\left(\mathrm{e}_{\mathrm{H}}^{+}\right)^{2} /\left(4 \mathrm{t}_{\mathrm{H}}\right)$. In this case,

$$
\begin{aligned}
\partial \mathrm{U}_{\mathrm{H}}^{\mathrm{II}} / \partial \lambda & =\left(\mathrm{P}^{+}-\mathrm{e}_{\mathrm{H}}^{+} / \mathrm{t}_{\mathrm{H}}\right)\left(\partial \mathrm{e}_{\mathrm{H}}^{+} / \partial \lambda\right) / 2+\left(\mathrm{t}_{\mathrm{H}}+\mathrm{e}_{\mathrm{H}}^{+}\right)\left(\partial \mathrm{P}^{+} / \partial \lambda\right) / 2 \\
& =\left[\left(\partial \mathrm{P}^{+} / \partial \lambda\right) / 2\right]\left[\mathrm{t}_{\mathrm{H}}+\mathrm{e}_{\mathrm{H}}^{+}+\left\{\left(\mathrm{t}_{\mathrm{H}}-\mathrm{t}_{\mathrm{L}}\right) \mathrm{P}^{+}-\left[2 \mathrm{t}_{\mathrm{L}}\left(\mathrm{t}_{\mathrm{H}}-\mathrm{t}_{\mathrm{L}}\right) \mathrm{P}^{+}\right]^{1 / 2}\right\}\left\{\mathrm{t}_{\mathrm{L}}+\left[\mathrm{t}_{\mathrm{L}}\left(\mathrm{t}_{\mathrm{H}}-\mathrm{t}_{\mathrm{L}}\right) / 2 \mathrm{P}^{+}\right]^{1 / 2}\right\} / \mathrm{t}_{\mathrm{H}}\right] .
\end{aligned}
$$

A sufficient condition for this expression to be positive is that $t_{H}+e_{H}^{+}+\left\{-\left[2 t_{L}\left(t_{H}-\right.\right.\right.$ $\left.\left.\left.\mathrm{t}_{\mathrm{L}}\right) \mathrm{P}^{+}\right]^{1 / 2}\right\}\left\{\mathrm{t}_{\mathrm{L}}+\left[\mathrm{t}_{\mathrm{L}}\left(\mathrm{t}_{\mathrm{H}}-\mathrm{t}_{\mathrm{L}}\right) / 2 \mathrm{P}^{+}\right]^{1 / 2}\right\} / \mathrm{t}_{\mathrm{H}}>0$; that is, if $\left\{\mathrm{e}_{\mathrm{H}}^{+}-\left(\mathrm{t}_{\mathrm{L}} / \mathrm{t}_{\mathrm{H}}\right)\left[2 \mathrm{t}_{\mathrm{L}}\left(\mathrm{t}_{\mathrm{H}}-\mathrm{t}_{\mathrm{L}}\right) \mathrm{P}^{+}\right]^{1 / 2}\right\}+\left\{\mathrm{t}_{\mathrm{H}}-\right.$ $\left.\left(t_{L} / t_{H}\right)\left(t_{H}-t_{L}\right)\right\}>0$. But both of the expressions in braces are positive, so $\partial \mathrm{U}_{\mathrm{L}}^{\mathrm{II}} / \partial \lambda>0$ when the SSPBE is distortionary.

iii) Since $U^{I I}=\lambda U_{H}^{I I}+(1-\lambda) U_{L}^{I I}$, it follows that 


$$
\partial \mathrm{U}^{\mathrm{II}} / \partial \lambda=\lambda\left(\partial \mathrm{U}_{\mathrm{H}}^{\mathrm{II}} / \partial \lambda\right)+(1-\lambda)\left(\partial \mathrm{U}_{\mathrm{L}}^{\mathrm{II}} / \partial \lambda\right)+\left(\mathrm{U}_{\mathrm{H}}^{\mathrm{II}}-\mathrm{U}_{\mathrm{L}}^{\mathrm{II}}\right) .
$$

Every term in this expression is positive by i) and ii), and thus $\partial \mathrm{U}^{\mathrm{II}} / \partial \lambda>0$.

\section{QED Proposition 3.}

\section{Proof of Proposition 5.}

(i) Recall that $\mathrm{e}_{\mathrm{rs}}=\mathrm{t}_{\mathrm{r}} \mathrm{t}_{\mathrm{s}}\left(1+\mathrm{t}_{\mathrm{r}}\right) /\left(1-\mathrm{t}_{\mathrm{r}} \mathrm{t}_{\mathrm{s}}\right), \mathrm{r}, \mathrm{s}=\mathrm{H}, \mathrm{L}$. The proof is trivial and therefore omitted. (ii) Recall that $\gamma\left(t_{H}, t_{L}\right)=\left[\Lambda\left(t_{H}, t_{L}\right), 1\right)$, and suppose that $\gamma\left(t_{H}, t_{L}\right)$ is non-empty; that is, $\Lambda\left(t_{\mathrm{H}}, \mathrm{t}_{\mathrm{L}}\right)<1$. Note that $\mathrm{e}_{\mathrm{HH}}>\mathrm{e}_{\mathrm{H}}^{0}$ if and only if $\mathrm{t}_{\mathrm{H}}{ }^{2} /\left(1-\mathrm{t}_{\mathrm{H}}\right)>\mathrm{t}_{\mathrm{H}} \mathrm{t} /(1-\overline{\mathrm{t}})$; this inequality holds for all $\lambda \in(0,1)$, and thus for all $\lambda \in \eta\left(\mathrm{t}_{\mathrm{H}}, \mathrm{t}_{\mathrm{L}}\right)$. Since $\mathrm{e}_{\mathrm{H}}^{0}>\mathrm{e}_{\mathrm{HL}}$ if and only if $\mathrm{t}_{\mathrm{H}} \bar{t} /(1-\overline{\mathrm{t}})>\mathrm{t}_{\mathrm{H}} \mathrm{t}_{\mathrm{L}}(1$ $\left.+t_{H}\right) /\left(1-t_{H} t_{L}\right)$, it follows (after some algebra) that $e_{H}^{0}>e_{H L}$ if and only if $\lambda>t_{L} /\left(1+t_{L}\right)$. Since $\mathrm{t}_{\mathrm{L}} /\left(1+\mathrm{t}_{\mathrm{L}}\right)<\Lambda\left(\mathrm{t}_{\mathrm{H}}, \mathrm{t}_{\mathrm{L}}\right)$, all $\lambda \in \eta\left(\mathrm{t}_{\mathrm{H}}, \mathrm{t}_{\mathrm{L}}\right)$ exceed $\mathrm{t}_{\mathrm{L}} /\left(1+\mathrm{t}_{\mathrm{L}}\right)$ and thus $\mathrm{e}_{\mathrm{H}}^{0}>\mathrm{e}_{\mathrm{HL}} \forall \lambda \epsilon$ $\left(t_{\mathrm{H}}, \mathrm{t}_{\mathrm{L}}\right)$.

(iii) Suppose that $\gamma\left(\mathrm{t}_{\mathrm{H}}, \mathrm{t}_{\mathrm{L}}\right)$ is non-empty; that is, $\Lambda\left(\mathrm{t}_{\mathrm{H}}, \mathrm{t}_{\mathrm{L}}\right)<1$. Note that $\mathrm{e}_{\mathrm{L}}^{0}>\mathrm{e}_{\mathrm{LL}}$ if and only if $\mathrm{t}_{\mathrm{L}} \overline{\mathrm{t}} /(1-\overline{\mathrm{t}})>\mathrm{t}_{\mathrm{L}}{ }^{2} /\left(1-\mathrm{t}_{\mathrm{L}}\right)$; this inequality holds for all $\lambda \in(0,1)$, and thus for all $\lambda \in \eta\left(\mathrm{t}_{\mathrm{H}}, \mathrm{t}_{\mathrm{L}}\right)$.

(iv) Suppose that $\gamma\left(t_{H}, t_{L}\right)$ is non-empty; that is, $\Lambda\left(t_{H}, t_{L}\right)<1$. Since $e_{L}^{0}(>=<) e_{L H}$ as $\mathrm{t}_{\mathrm{L}} \mathrm{t} /(1-\overline{\mathrm{t}})>\mathrm{t}_{\mathrm{L}} \mathrm{t}_{\mathrm{H}}\left(1+\mathrm{t}_{\mathrm{L}}\right) /\left(1-\mathrm{t}_{\mathrm{H}} \mathrm{t}_{\mathrm{L}}\right)$, it follows (after some algebra) that $\mathrm{e}_{\mathrm{L}}^{0}(>=<) \mathrm{e}_{\mathrm{LH}}$ as $\lambda$ $(>=<) 1 /\left(1+\mathrm{t}_{\mathrm{H}}\right)$. In particular, $\mathrm{e}_{\mathrm{L}}^{0} \geq \mathrm{e}_{\mathrm{LH}}$ for $\left.\lambda \in\left[\max \left\{\Lambda\left(\mathrm{t}_{\mathrm{H}}, \mathrm{t}_{\mathrm{L}}\right), 1 /\left(1+\mathrm{t}_{\mathrm{H}}\right)\right)\right\}, 1\right)$ (this interval is always non-empty) and $\mathrm{e}_{\mathrm{L}}^{0}<\mathrm{e}_{\mathrm{LH}}$ for $\lambda \in\left[\Lambda\left(\mathrm{t}_{\mathrm{H}}, \mathrm{t}_{\mathrm{L}}\right), 1 /\left(1+\mathrm{t}_{\mathrm{H}}\right)\right.$ ) (this interval may be empty). (v) Let us review several results that will be used in the proof. (a) At any point $\left(t_{\mathrm{H}}, \mathrm{t}_{\mathrm{L}}\right)$ such that $\Lambda\left(t_{H}, t_{L}\right)>1$, the SSPBE will be distortionary for all $\lambda \in(0,1)$; (b) since the equation $t_{L}$ $=t_{H}^{2} /\left(2-t_{H}\right)$ defines the locus $\Lambda\left(t_{H}, t_{L}\right)=1$ and since $\Lambda\left(t_{H}, t_{L}\right)$ is increasing in $t_{L}$ for fixed $\mathrm{t}_{\mathrm{H}}$, the fact that $\Lambda\left(\mathrm{t}_{\mathrm{H}}, \mathrm{t}_{\mathrm{L}}\right)>1$ implies that $\mathrm{t}_{\mathrm{L}}>\mathrm{t}_{\mathrm{H}}{ }^{2} /\left(2-\mathrm{t}_{\mathrm{H}}\right)$; and (c) $\mathrm{P}^{*}=\mathrm{P}^{+}>\mathrm{P}^{0}$ for all $\lambda \in(0,1)$ (this inequality was obtained in the proof of Lemma 2). Now $\mathrm{e}_{\mathrm{H}}^{+}>\mathrm{e}_{\mathrm{HH}}$ if and only if $\mathrm{g}(\lambda) \equiv$ $\mathrm{t}_{\mathrm{L}} \mathrm{P}^{+}+\left[2 \mathrm{t}_{\mathrm{L}}\left(\mathrm{t}_{\mathrm{H}}-\mathrm{t}_{\mathrm{L}}\right) \mathrm{P}^{+}\right]^{1 / 2}-\mathrm{t}_{\mathrm{H}}^{2} /\left(1-\mathrm{t}_{\mathrm{H}}\right)>0$. Note that $\lim _{\lambda \rightarrow 0} \mathrm{~g}(\lambda)<0$ but $\mathrm{g}^{\prime}(\lambda)>0$. We will show that $\lim _{\lambda \rightarrow 1} g(\lambda)>0$. Since $g(\lambda)>t_{L} P^{0}+\left[2 t_{L}\left(t_{H}-t_{L}\right) P^{0}\right]^{1 / 2}-t_{H}^{2} /\left(1-t_{H}\right)$ for all $\lambda \in(0,1)$, $\lim _{\lambda \rightarrow 1} g(\lambda) \geq \lim _{\lambda \rightarrow 1} t_{L} P^{0}+\left[2 t_{L}\left(t_{H}-t_{L}\right) P^{0}\right]^{1 / 2}-t_{H}^{2} /\left(1-t_{H}\right)=t_{L} t_{H} /\left(1-t_{H}\right)+\left[2 t_{L}\left(t_{H}-t_{L}\right) t_{H} /\left(1-t_{H}\right)\right]^{1 / 2}$ $-t_{\mathrm{H}}^{2} /\left(1-t_{\mathrm{H}}\right)>0$. (This last inequality follows from the fact that $t_{\mathrm{L}}>\mathrm{t}_{\mathrm{H}}^{2} /\left(2-\mathrm{t}_{\mathrm{H}}\right)$ ).

(vi) Note that $e_{L}^{+}>e_{L_{L}}$ if and only if $h(\lambda) \equiv t_{L} P^{+}-t_{L}{ }^{2} /\left(1-t_{L}\right)>0$. But since $P^{+}>\bar{t} /\left(1-t_{L}\right)$, it follows that $h(\lambda)>t_{L} t /\left(1-t_{L}\right)-t_{L}^{2} /\left(1-t_{L}\right)>0$ for all $\lambda \in(0,1)$ and thus for all $\lambda \in \&\left(t_{H}, t_{L}\right)$. (vii) Note that $\mathrm{e}_{\mathrm{L}}^{+}>\mathrm{e}_{\mathrm{LH}}$ if and only if $\mathrm{k}(\lambda) \equiv \mathrm{t}_{\mathrm{L}} \mathrm{P}^{+}-\mathrm{t}_{\mathrm{L}} \mathrm{t}_{\mathrm{H}}\left(1+\mathrm{t}_{\mathrm{L}}\right) /\left(1-\mathrm{t}_{\mathrm{H}} \mathrm{t}_{\mathrm{L}}\right)=\left[\mathrm{t}_{\mathrm{L}} /\left(1-\mathrm{t}_{\mathrm{L}}\right)\right][\overline{\mathrm{t}}+\lambda \mathrm{Y}]$ $-t_{L} t_{H}\left(1+t_{L}\right) /\left(1-t_{H} t_{L}\right)>0$, where $Y$ is as defined above in the construction of the equilibrium. Let $\mathrm{Y}(1) \equiv \lim _{\lambda \rightarrow 1} \mathrm{Y}(\lambda)$, and notice that $\mathrm{Y}(1)>\mathrm{t}_{\mathrm{L}}\left(\mathrm{t}_{\mathrm{H}}-\mathrm{t}_{\mathrm{L}}\right) /\left(1-\mathrm{t}_{\mathrm{L}}\right) . \operatorname{Lim}_{\lambda \rightarrow 0} \mathrm{k}(\lambda)<0$ but $\mathrm{k}^{\prime}(\lambda)>$ 0 . We will show that $\lim _{\lambda \rightarrow 1} \mathrm{k}(\lambda)>0$. We can write $\lim _{\lambda \rightarrow 1} \mathrm{k}(\lambda)=\left[\mathrm{t}_{\mathrm{L}} /\left(1-\mathrm{t}_{\mathrm{L}}\right)\right]\left[\mathrm{t}_{\mathrm{H}}+\mathrm{Y}(1)\right]-$ $\mathrm{t}_{\mathrm{L}} \mathrm{t}_{\mathrm{H}}\left(1+\mathrm{t}_{\mathrm{L}}\right) /\left(1-\mathrm{t}_{\mathrm{H}} \mathrm{t}_{\mathrm{L}}\right)>\left[\mathrm{t}_{\mathrm{L}} /\left(1-\mathrm{t}_{\mathrm{L}}\right)\right]\left[\mathrm{t}_{\mathrm{H}}+\mathrm{t}_{\mathrm{L}}\left(\mathrm{t}_{\mathrm{H}}-\mathrm{t}_{\mathrm{L}}\right) /\left(1-\mathrm{t}_{\mathrm{L}}\right)\right]-\mathrm{t}_{\mathrm{L}} \mathrm{t}_{\mathrm{H}}\left(1+\mathrm{t}_{\mathrm{L}}\right) /\left(1-\mathrm{t}_{\mathrm{H}} \mathrm{t}_{\mathrm{L}}\right)>0$ (following some algebra).

QED Proposition 5. 


\section{References}

Akerlof, George. "The Economics of Caste and of the Rat Race and Other Woeful Tales," Quarterly Journal of Economics 90 (1976), 599-617.

Bagwell, Kyle and Garey Ramey. "Oligopoly Limit Pricing,” RAND Journal of Economics 22 (1991), 155-172.

Bar-Isaac, Heski. "Something to Prove: Reputation in Teams," working paper, New York University, November 2004.

Caillaud, Bernard and Benjamin Hermalin. "The Use of an Agent in a Signaling Model," Journal of Economic Theory 60 (1993), pp. 83-113.

Chou, Eric S. "The Boundaries of the Firms as Information Barriers," RAND Journal of Economics, forthcoming.

Das Varma, Gopal. "Bidding for a Process Innovation under Alternative Modes of Competition," International Journal of Industrial Organization 21 (2003), 15-37.

Daughety, Andrew F. and Jennifer F. Reinganum. "Product Safety: Liability, R\&D and Signaling," American Economic Review 85 (1995), 1187-1206.

Daughety, Andrew F. and Jennifer F. Reinganum. "Secrecy and Safety," American Economic Review 95 (2005a), 1074-91.

Daughety, Andrew F. and Jennifer F. Reinganum. "Competition and Confidentiality: Signaling Quality in a Duopoly When There is Universal Private Information," forthcoming, Games and Economic Behavior.

Daughety, Andrew F. and Jennifer F. Reinganum, "Imperfect Competition and Quality Signaling," Vanderbilt University Working Paper No. 05-W20, June 2005 b.

Dewatripont, Mathias, Ian Jewitt, and Jean Tirole. "The Economics of Career Concerns, Part I: Comparing Information Structures," Review of Economic Studies 66 (1999), 183-198.

Fluet, Claude and Paolo G. Garella. "Advertising and Prices as Signals of Quality in a Regime of Price Rivalry,” International Journal of Industrial Organization 20 (2002), 907-930.

Fudenberg, Drew and Jean Tirole, Game Theory, Cambridge, MA: MIT Press, 1991.

Gervais, Simon and Itay Goldstein, "The Positive Effects of Biased Self-Perceptions in Teams," working paper, January 2006. 
Grossman, Sanford J. and Oliver D. Hart, "The Costs and Benefits of Ownership: A Theory of Vertical and Lateral Integration,” Journal of Political Economy 94 (1986), 691-719.

Harrington, Joseph E., Jr. “Oligopolistic Entry Deterrence Under Incomplete Information,” RAND Journal of Economics 18 (1987), 211-231.

Hart, Oliver D. and John Moore, "Property Rights and the Nature of the Firm," Journal of Political Economy 98 (1990), 1119-1158.

Hermalin, Benjamin E. "Toward an Economic Theory of Leadership: Leading by Example," American Economic Review 88 (1998), pp. 1188-1206.

Hertzendorf, Mark N. and Per Baltzer Overgaard. "Price Competition and Advertising Signals: Signaling by Competing Senders," Journal of Economics and Management Strategy 10 (2001b), 621-662.

Levin, Jonathan and Steven Tadelis. "Profit Sharing and the Role of Professional Partnerships," Quarterly Journal of Economics 120 (2005), 131-171.

Levy, Gilat. "Careerist Judges and the Appeals Process," RAND Journal of Economics 36 (2005), 275-197.

Levy, Gilat. “Anti-Herding and Strategic Consultation,” European Economic Review 48 (2004), 503-525.

Mailath, George J. "An Abstract Two-Period Game with Simultaneous Signaling - Existence of Separating Equilibria," Journal of Economic Theory 46 (1988), 373-394.

Mailath, George J. "Simultaneous Signaling in an Oligopoly Model," Quarterly Journal of Economics 104 (1989), 417-427.

Martin, Stephen. "Oligopoly Limit Pricing: Strategic Substitutes, Strategic Complements," International Journal of Industrial Organization 13 (1995), 41-65.

Matthews, Steven A. and Leonard J. Mirman. "Equilibrium Limit Pricing: The Effects of Private Information and Stochastic Demand,” Econometrica 51 (1983), 981-996.

Morrison, Alan D. and William J. Wilhelm, Jr. "Partnership Firms, Reputation, and Human Capital," American Economic Review 94 (2004), 1682-1692.

Orzach, Ram and Yair Tauman. "Signalling Reversal,” International Economic Review 37 (1996), 453-464.

Scharfstein, David S. and Jeremy C. Stein. "Herd Behavior and Investment," American Economic Review 80 (1990), 465-479. 
Vives, Xavier. "Complementarities and Games: New Developments," Journal of Economic Literature 43 (2005), 437-479.

Zwiebel, Jeffrey. "Corporate Conservatism and Relative Compensation," Journal of Political Economy 103 (1995), 1-25. 


\section{Supplementary Appendix for \\ "Hidden Talents: Partnerships with Pareto-Improving Private Information" Andrew F. Daughety and Jennifer F. Reinganum}

Claim concerning $\mathrm{U}^{\mathrm{CI}} . \mathrm{U}^{\mathrm{CI}}$ is strictly increasing in $\lambda$.

Proof of Claim. Recall that $\mathrm{U}^{\mathrm{CI}} \equiv \lambda^{2} \mathrm{u}_{\mathrm{HH}}+\lambda(1-\lambda) \mathrm{u}_{\mathrm{HL}}+(1-\lambda) \lambda \mathrm{u}_{\mathrm{LH}}+(1-\lambda)^{2} \mathrm{u}_{\mathrm{LL}}$, where $\mathrm{u}_{\mathrm{HH}}>\mathrm{u}_{\mathrm{HL}}$ $>\mathrm{u}_{\mathrm{LH}}>\mathrm{u}_{\mathrm{LL}}$. Alternatively, $\mathrm{U}^{\mathrm{Cl}}=\lambda\left[\lambda \mathrm{u}_{\mathrm{HH}}+(1-\lambda) \mathrm{u}_{\mathrm{HL}}\right]+(1-\lambda)\left[\lambda \mathrm{u}_{\mathrm{LH}}+(1-\lambda) \mathrm{u}_{\mathrm{LL}}\right]$. Since the expressions $\mathrm{u}_{\mathrm{rs}}$ (for $\mathrm{r}, \mathrm{s}=\mathrm{H}, \mathrm{L}$ ) are independent of $\lambda$,

$$
\begin{aligned}
\partial \mathrm{U}^{\mathrm{Cl}} / \partial \lambda & =\left[\lambda \mathrm{u}_{\mathrm{HH}}+(1-\lambda) \mathrm{u}_{\mathrm{HL}}\right]-\left[\lambda \mathrm{u}_{\mathrm{LH}}+(1-\lambda) \mathrm{u}_{\mathrm{LL}}\right]+\lambda\left[\mathrm{u}_{\mathrm{HH}}-\mathrm{u}_{\mathrm{HL}}\right]+(1-\lambda)\left[\mathrm{u}_{\mathrm{LH}}-\mathrm{u}_{\mathrm{LL}}\right] \\
& =\lambda\left[\mathrm{u}_{\mathrm{HH}}-\mathrm{u}_{\mathrm{LH}}\right]+(1-\lambda)\left[\mathrm{u}_{\mathrm{HL}}-\mathrm{u}_{\mathrm{LL}}\right]+\lambda\left[\mathrm{u}_{\mathrm{HH}}-\mathrm{u}_{\mathrm{HL}}\right]+(1-\lambda)\left[\mathrm{u}_{\mathrm{LH}}-\mathrm{u}_{\mathrm{LL}}\right]>0
\end{aligned}
$$

where the final inequality follows since each term in brackets is positive. QED Claim.

Claim concerning $\Lambda\left(t_{H}, t_{L}\right)$ : The critical value $\Lambda\left(t_{H}, t_{L}\right) \equiv t_{L}\left(2-\left(t_{H}+t_{L}\right)\right) /\left(\left(t_{H}+t_{L}\right)\left(t_{H}-t_{L}\right)\right)$ is strictly increasing in $t_{L}$ for fixed $t_{H}$.

Proof of Claim. Differentiation implies that $\partial \Lambda\left(t_{H}, t_{L}\right) / \partial t_{L}=\left[\left(2-t_{H}\right)\left(t_{H}{ }^{2}+t_{L}^{2}\right)-2 t_{L} t_{H}{ }^{2}\right] /\left(t_{H}{ }^{2}-t_{L}^{2}\right)^{2}$. The numerator is positive as long as $\mathrm{w}\left(\mathrm{t}_{\mathrm{L}}\right) \equiv 2-\mathrm{t}_{\mathrm{H}}-2 \mathrm{t}_{\mathrm{L}} \mathrm{t}_{\mathrm{H}}{ }^{2} /\left(\mathrm{t}_{\mathrm{H}}{ }^{2}+\mathrm{t}_{\mathrm{L}}{ }^{2}\right)>0$. We will show that $\mathrm{w}\left(\mathrm{t}_{\mathrm{L}}\right)>0$ for all $\mathrm{t}_{\mathrm{L}} \in\left(0, \mathrm{t}_{\mathrm{H}}\right)$. To see this, note that $\mathrm{w}(0)=2-\mathrm{t}_{\mathrm{H}}>0$ and that $\mathrm{w}^{\prime}\left(\mathrm{t}_{\mathrm{L}}\right)=-2 \mathrm{t}_{\mathrm{H}}{ }^{2}\left(\mathrm{t}_{\mathrm{H}}{ }^{2}\right.$ $\left.-t_{\mathrm{L}}{ }^{2}\right) /\left(\mathrm{t}_{\mathrm{H}}{ }^{2}+\mathrm{t}_{\mathrm{L}}{ }^{2}\right)^{2}<0$. Thus, the "worst-case scenario"involves the limit as $\mathrm{t}_{\mathrm{L}}$ approaches $\mathrm{t}_{\mathrm{H}}$. But $\mathrm{w}\left(\mathrm{t}_{\mathrm{H}}\right)=2-2 \mathrm{t}_{\mathrm{H}}>0$ for all $\mathrm{t}_{\mathrm{H}}<1$. Thus, $\mathrm{w}\left(\mathrm{t}_{\mathrm{L}}\right)$ starts out positive and decreases as $\mathrm{t}_{\mathrm{L}}$ increases, approaching a positive limit (from above) as $t_{L}$ approaches $t_{H}$. Thus, $\partial \Lambda\left(t_{H}, t_{L}\right) / \partial t_{L}$ $>0$ for all $t_{L} \in\left(0, t_{H}\right)$. QED Claim.

\section{$\underline{\text { Sole-producer model }}$}

As we have noted in the text, in single-agent signaling models it is typical that (a) the separating equilibrium depends only on the support of the distribution, not the prior over that support; and (b) the agent is worse off under incomplete information than under complete information because, although the L-type chooses her complete information action, the H-type's equilibrium action is typically distorted. These features apply to a sole-producer version of our model as well.

Suppose that the project requires only one worker's effort, with the value of the project equal to the worker's productivity $(\mathrm{t}+\mathrm{e})$. Using the notation from the text, under complete information, the type-dependent payoff functions are:

$$
u\left(e_{r}, t_{r}, t_{r}\right) \equiv\left(t_{r}+e_{r}\right)-\left(e_{r}\right)^{2} /\left(4 t_{r}\right), r=H, L .
$$

Note that the true type and the perceived type are the same under complete information. The complete-information optimal effort levels are given by $e_{r}=2 t_{r}, r=H, L$.

In the case of incomplete information, the worker's payoff is: 


$$
u(e, t, \mathfrak{t}) \equiv(\mathfrak{t}+e)-(e)^{2} /(4 t)
$$

where the true type $t$ and the perceived type $\tilde{t}$ need not be the same. The incentive compatibility constraints now become:

$$
\left(t_{H}+e_{H}\right)-\left(1 / 4 t_{H}\right)\left(e_{H}\right)^{2} \geq\left(t_{L}+2 t_{H}\right)-\left(1 / 4 t_{H}\right)\left(2 t_{H}\right)^{2},
$$

which is satisfied for all $\mathrm{e}_{\mathrm{H}}$ in the closed interval:

$$
\left[\hat{\mathrm{e}}^{-}, \hat{\mathrm{e}}^{+}\right]=\left[2 \mathrm{t}_{\mathrm{H}}-2\left[\mathrm{t}_{\mathrm{H}}\left(\mathrm{t}_{\mathrm{H}}-\mathrm{t}_{\mathrm{L}}\right)\right]^{1 / 2}, 2 \mathrm{t}_{\mathrm{H}}+2\left[\mathrm{t}_{\mathrm{H}}\left(\mathrm{t}_{\mathrm{H}}-\mathrm{t}_{\mathrm{L}}\right)\right]^{1 / 2}\right] ;
$$

and:

$$
\left(t_{L}+2 t_{L}\right)-\left(1 / 4 t_{L}\right)\left(2 t_{L}\right)^{2} \geq\left(t_{H}+e_{H}\right)-\left(1 / 4 t_{L}\right)\left(e_{H}\right)^{2},
$$

which is satisfied for all $\mathrm{e}_{\mathrm{H}}$ not in the open interval:

$$
\left(\tilde{\mathrm{e}}^{-}, \tilde{\mathrm{e}}^{+}\right)=\left(2 \mathrm{t}_{\mathrm{L}}-2\left[\mathrm{t}_{\mathrm{L}}\left(\mathrm{t}_{\mathrm{H}}-\mathrm{t}_{\mathrm{L}}\right)\right]^{1 / 2}, 2 \mathrm{t}_{\mathrm{L}}+2\left[\mathrm{t}_{\mathrm{L}}\left(\mathrm{t}_{\mathrm{H}}-\mathrm{t}_{\mathrm{L}}\right)\right]^{1 / 2}\right) .
$$

The following are candidates for the H-type's equilibrium strategy (respecting the requirement of no mimicry): $\mathrm{e}_{\mathrm{H}} \in\left[\hat{\mathrm{e}}^{-}, \widetilde{\mathrm{e}}\right] \cup\left[\widetilde{\mathrm{e}}^{+}, \hat{\mathrm{e}}^{+}\right]$. The interval $\left[\hat{\mathrm{e}}^{-}, \tilde{\mathrm{e}}^{-}\right]$can be shown to be empty, while the interval $\left[\widetilde{\mathrm{e}}^{+}, \hat{\mathrm{e}}^{+}\right]$is always non-empty. The interval $\left[\tilde{\mathrm{e}}^{+}, \hat{\mathrm{e}}^{+}\right]$may contain the H-type's complete-information optimal effort $\mathrm{e}=2 \mathrm{t}_{\mathrm{H}}$; in this case, the H-type can deter mimicry without distorting her effort (that is, analogous to the NPBE equilibrium in the main text when there are two partners). Otherwise she will distort her effort to the least extent necessary to deter mimicry; that is, to $\mathrm{e}=\tilde{\mathrm{e}}^{+}$(analogous to the DPBE equilibrium in the main text). Thus, the H-type's separating equilibrium effort level is given by $\mathrm{e}_{\mathrm{H}}^{*}=2 \mathrm{t}_{\mathrm{H}}$ if $\mathrm{t}_{\mathrm{L}} \leq \mathrm{t}_{\mathrm{H}} / 2$ and $\mathrm{e}_{\mathrm{H}}^{*}=2 \mathrm{t}_{\mathrm{L}}+2\left[\mathrm{t}_{\mathrm{L}}\left(\mathrm{t}_{\mathrm{H}}-\mathrm{t}_{\mathrm{L}}\right)\right]^{1 / 2}$ if $\mathrm{t}_{\mathrm{L}}>\mathrm{t}_{\mathrm{H}} / 2$. Note that $2 t_{L}+2\left[t_{L}\left(t_{H}-t_{L}\right)\right]^{1 / 2}>2 t_{H}$, so that when $t_{L}>t_{H} / 2$, the equilibrium requires the H-type to distort effort to a level in excess of the complete-information level, which means that the H-type chooses an effort level where profits for such a type are falling in effort. The L-type's separating equilibrium effort level is given by $\mathrm{e}_{\mathrm{L}}^{*}=2 \mathrm{t}_{\mathrm{L}}$. Note that the separating equilibrium effort levels depend on the support of the prior distribution, but not on $\lambda$. Moreover, when $t_{L}>t_{H} / 2$ the H-type distorts her effort level upward from her monopoly level; thus the worker's ex ante expected payoff under incomplete information is always lower than under complete information. 